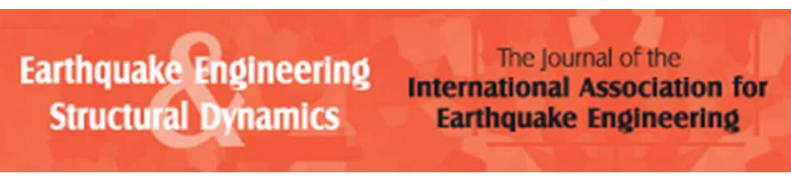

\title{
Comparing Fluid Viscous Damper Placement Methods Considering Total-Building Seismic Performance
}

\begin{tabular}{|r|l|}
\hline Journal: & Earthquake Engineering and Structural Dynamics \\
\hline Manuscript ID & EQE-17-0492.R3 \\
\hline Wiley - Manuscript type: & Research Article \\
\hline Complete List of Authors: & $\begin{array}{l}\text { Del Gobbo, Giuseppe; University of Oxford, Dept of Engineering Science } \\
\text { Williams, Martin; University of Oxford, Dept of Engineering Science } \\
\text { Blakeborough, Anthony; University of Oxford, Dept of Engineering Science }\end{array}$ \\
\hline Keywords: & $\begin{array}{l}\text { Fluid Viscous Dampers, Damper placement, FEMA P-58, Nonstructural } \\
\text { Systems }\end{array}$ \\
\hline \multicolumn{2}{|c}{} \\
\hline
\end{tabular}




\section{Introduction}

Nonstructural damage has been found to critically influence economic losses and building downtime following earthquakes in the 1990s to 2010s.$^{1-6}$ Attaining a target level of seismic performance mandates the harmonization of structural and nonstructural performance. FEMA P-58 analyses conducted by Del Gobbo et al. ${ }^{8,9}$ revealed that Eurocode ${ }^{10}$-compliant concentric braced frame (CBF) structures are likely to experience extensive damage during both ultimate limit state (ULS) and serviceability limit state (SLS) earthquakes. The ULS earthquake, or the Eurocode 8 no-collapse requirement, has a $10 \%$ probability of exceedance in 50 years. Structures are designed to withstand the ULS seismic action while retaining structural integrity after the earthquake. The SLS earthquake, or the Eurocode 8 damage limitation requirement, has a $10 \%$ probability of exceedance in 10 years. Damage at the SLS should be limited to a point that does not compromise building serviceability. ${ }^{11}$

Retrofitting buildings with supplemental damping devices can substantially reduce interstorey drifts and improve the seismic performance of buildings. Fluid viscous dampers (FVDs) have been identified as the most promising of these devices for nonstructural considerations as they can improve both interstorey drifts and floor accelerations. ${ }^{12-19}$

The distribution of dampers within a building is a critical decision, as damper placement affects structural response and the required damper investment. While many FVD placement methods have been proposed, only limited comparisons of methods have been conducted. ${ }^{20-27}$ Research comparing FVD placement methods has evaluated structural parameters rather than repair costs. Complexities arise as structural parameters are often competing objectives (e.g. interstorey drift and floor acceleration), while limitations are introduced when determining appropriate parameter weights to represent the performance. As a result, an optimal placement technique is often not conclusively identified due to performance variations between storeys and between structural parameters. The use of repair costs is an appropriate measure of total-building seismic performance that avoids the limitations of structural parameters and damage indices. ${ }^{8}$ Other common limitations include the use of simplified shear building models, the use of a limited set of ground motions, the selection of only a small number of different placement techniques, and the omission of SLS performance. This study is the first to compare damper placement methods considering repair costs calculated using FEMA P-58, and addresses the identified limitations of previous research.

This paper evaluates and compares the effectiveness of several damper placement methods considering structural and nonstructural performance in repair costs. Four-, eight- and 16-storey Eurocode-compliant building designs from the Del Gobbo et al. study ${ }^{8}$ were considered. Six frequently used damper placement methods were selected for the investigation based on prevalence in literature and level of practicality. The structures are modelled 
and time history analyses are conducted using OpenSees. ${ }^{28}$ The seismic performance of the FVD-retrofitted buildings is evaluated considering structural engineering demand parameters (EDPs), nonlinear structural behavior, and repair costs using the FEMA P-58 seismic performance assessment procedure. $^{7}$

Due to the novelty of this paper, the scope is limited to linear FVDs. While nonlinear FVDs are often used in practice, their use here would significantly increase the number of optimization parameters and would be inappropriate for this preliminary study. Consideration of nonlinear dampers would be a valuable future extension to the current work. The scope of this paper is also limited to regular, CBF structures. The following discussion should be considered in this light and only extended to other types of structure cautiously.

\section{Description of Eurocode Buildings}

Four-, eight- and 16-storey Eurocode ${ }^{10}$-compliant building designs from the Del Gobbo et al. study $^{8}$ were considered, referred to as buildings $4 \mathrm{~S}, 8 \mathrm{~S}$ and $16 \mathrm{~S}$ respectively. The buildings were designed to be representative of steel CBF structures designed using modern codes for regions with significant seismic hazard. Previous studies have focused on shear or moment-resisting frame buildings, while this paper is limited to regular CBF buildings.

The suite of office buildings were designed to resist dead, imposed, snow, wind and seismic loads using the Eurocodes. ${ }^{10,11,29,30}$ A PGA of $0.306 \mathrm{~g}$ was selected for the building site. Full design information and section details are available in the Del Gobbo et al. ${ }^{8}$ study. Elevations of the structures are shown in Figure 1, with locations of FVDs (if present) indicated in red. Figure 2 provides plan views of the structures. The four-storey building only required two braced bays in each direction to meet the interstorey drift limit. Table 1 and 2 provide the periods and modal mass participation factors of the buildings, respectively.
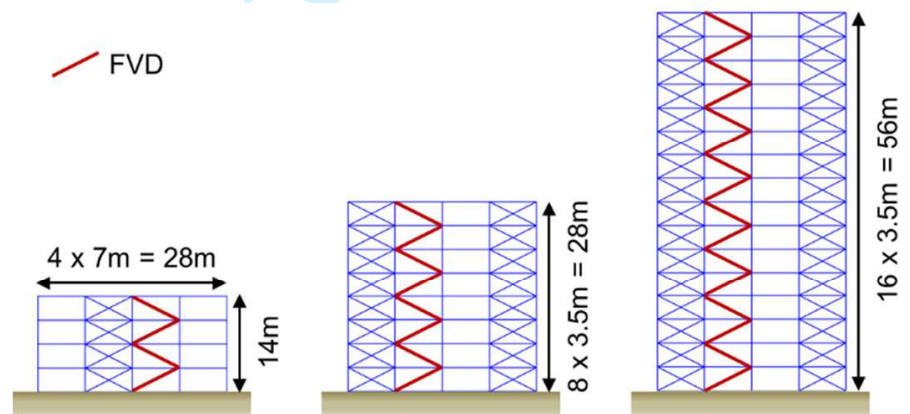

Figure 1: Elevation of office buildings with locations of fluid viscous dampers (FVDs)

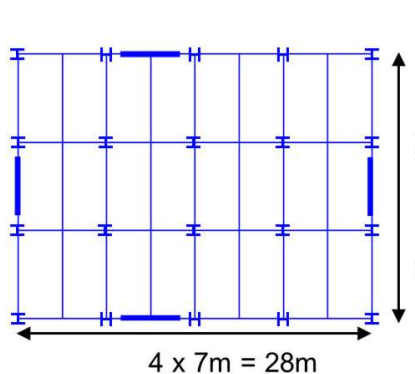

(a) Four-storey building

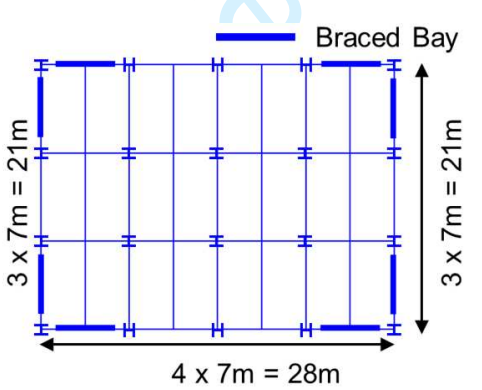

Figure 2: Plan views of the office buildings

Table 1: Periods

\begin{tabular}{lrrr}
\hline Mode & $\mathbf{4 S}$ & $\mathbf{8 S}$ & $\mathbf{1 6 S}$ \\
\hline 1 & $0.52 \mathrm{~s}$ & $0.97 \mathrm{~s}$ & $2.34 \mathrm{~s}$ \\
2 & $0.20 \mathrm{~s}$ & $0.32 \mathrm{~s}$ & $0.67 \mathrm{~s}$ \\
3 & $0.12 \mathrm{~s}$ & $0.18 \mathrm{~s}$ & $0.35 \mathrm{~s}$ \\
\hline
\end{tabular}

Table 2: Modal mass participation factors 


\section{OpenSees Modelling}

The structures are modelled in the program OpenSees. ${ }^{28}$ A leaning column ${ }^{31-34}$ was included to capture P-Delta effects from the gravity columns. Distributed plasticity force-based beam-column elements were used to model columns with Gauss-Lobatto integration and five integration points. Column sections were modelled using 12 fibers for major axis bending and 40 fibers for minor axis bending. ${ }^{35}$

Braces are modelled using the Uriz et al. physical-theory model. ${ }^{36}$ The SHS sections are modelled using five fiber layers across the depth of each flange and along the web, and two layers in the width. The MenegottoPinto material with a yield stress of $355 \mathrm{MPa}$ and a strain-hardening ratio of $0.3 \%$ was assigned to the fibers. ${ }^{32}$ Each brace was modelled using two elements with an initial imperfection of $0.1 \%$ at the midspan, three integration points, and a fictitious force at the midspan developing $5 \%$ of the yield moment to enable brace buckling. ${ }^{32}$

Dampers are modelled as linear viscous dashpots using the "twoNodeLink" element with the "Viscous" material. Inherent damping of 5\% was considered using mass and tangent stiffness proportional Rayleigh damping. Although lower values can be used, the value of $5 \%$ damping was selected to match the default for the Eurocode 8 horizontal response spectrum and is consistent with several previous studies. ${ }^{37-39}$

Time history analyses of the OpenSees models were conducted using ground motion records obtained from the PEER ground motion database. ${ }^{40}$ Two suites of 25 ground motions, one representing the ULS and one representing the SLS, were compiled for each building. The Eurocode $8^{11}$ response spectrum was used to select and scale records with the smallest mean squared error (MSE) between the ground motion spectrum and the target spectrum over the period range of $0.2 T_{I}$ and $2 T_{l} \cdot{ }^{40} \mathrm{~A}$ factor of 0.5 was used to define the SLS spectrum. All information for the ground motion suites is available in the Del Gobbo et al. study. ${ }^{8}$

\section{Selected Damper Placement Methods}

In addition to producing an efficient damper distribution, it is desirable that damper placement methods are practical enough to be used routinely by practicing engineers. The scope of this paper excludes placement methods that require extensive problem-specific tailoring or rely on complex tools and techniques not familiar to practicing engineers. Based on discussion with practicing engineers, the authors are of the opinion that these characteristics inhibit the common uptake of a method in practice, as the method cannot be easily incorporated into the design process. One such method is the algorithm for minimum transfer functions proposed by Takewaki. ${ }^{21}$ Other simple distributions such as mass proportional and interstorey drift proportional determined on the basis of the first mode deformations were excluded as they have been shown to be inferior. ${ }^{25}$

Six damper placement methods were selected for comparison. They include iterative methods as well as simple methods. Each of these methods were chosen based on prevalence in literature and level of practicality. A brief description of each method follows. The damper placement methods considered are:

1. Uniform damping

2. Stiffness proportional damping

3. The storey shear strain energy method (SEM) $)^{22}$

4. The efficient storey shear strain energy method (ESEM) ${ }^{22}$

5. The simplified sequential search algorithm (SSSA) $)^{23}$

6. The fully stressed design algorithm (FSDA) ${ }^{26}$

Uniform damping evenly distributes the total viscous damping coefficient between each storey. This simple technique is one of the most commonly used placement methods in research and often serves as a benchmark. ${ }^{14,22,24,25,41,42}$ Equation 1 is used to calculate $c_{j}$, the damping coefficient at storey $j$, where $C_{\text {total }}$ is the total viscous damper coefficient added to the structure and $n$ is the number of storeys.

$$
c_{j}=\frac{C_{\text {total }}}{n}
$$

Equation 1

Stiffness proportional damping distributes the damping coefficient in proportion to the relative storey stiffness. This placement method typically results in damper coefficients concentrated in the lower storeys. Stiffness proportional damping serves as a preliminary measure of advanced placement techniques implemented in regular structures, as many proposed methods have minimal damping in the upper storeys and concentrate dampers near the bottom of the structure. ${ }^{20}$ Equation 2 presents the method, where $K_{j}$ is the stiffness of storey $j$ and $i$ is each storey. 


$$
c_{j}=\frac{K_{j}}{\sum_{i} K_{i}} C_{\text {total }}
$$

The $\mathrm{SEM}^{22}$ distributes the damping coefficient along the building height in proportion to the storey shear strain energy corresponding to the first mode of the structure. Equation 3 is used to calculate $c_{j}$, where $\phi_{r j}$ is the relative modal displacement of storey $j$ and $S_{j}$ is a storey parameter proportional to the shear force $=\sum_{i=j}^{r o o f} m_{i} \phi_{i}$, where $m_{i}$ is the mass of the $i$ th-storey and $\phi_{i}$ is the modal displacement.

$$
c_{j}=\frac{S_{j} \phi_{r j}}{\sum_{i} S_{i} \phi_{r i}} C_{t o t a l}
$$

Equation 3

The ESEM ${ }^{22}$ is a modification of the SEM. The damping coefficient is allocated only to the storeys with a shear strain energy greater than the average storey shear strain energy, i.e. $S_{\mathrm{j}} \phi_{\mathrm{rj}}>\frac{1}{\mathrm{n}} \sum_{\mathrm{i}} S_{i} \phi_{r i}$. Equation 4 is used to distribute the damping coefficient to the "efficient" storeys, where $k$ is the number of storeys whose shear strain energy is greater than the average storey shear strain energy and $z$ refers to all storeys meeting that condition.

$$
c_{j}=\frac{S_{j} \phi_{r j}}{\sum_{z=1}^{k} S_{z} \phi_{r z}} C_{\text {total }}
$$

Equation 4

Two iterative techniques are studied: the $\operatorname{SSSA}^{23}$ and the $\mathrm{FSDA}^{26}$. The SSSA places an incremental damping coefficient sequentially in the storey with a maximum location index. The location index is peak interstorey velocity for linear FVDs. The FSDA is an analysis and redesign procedure that uses a recurrence relationship to allocate damping coefficients to each storey based on a performance index. The recurrence relationship is a function of interstorey drift for linear cases. These damper placement methods are examined in detail in Section 5.1 and 5.2.

The considered placement methods use linear structural response to optimize damper placement. However, the structural models in this paper capture nonlinear response that would be expected in the constructed structure. The performance of each FVD retrofitted structure can therefore be expected to deviate from the linear behavior assumed by the placement methods.

This study is limited to the placement of linear FVDs. Horizontal damper placement within each storey of the building is not considered, as most damper placement methods produce a vertical distribution of dampers within a structure. In order to compare the selected placement techniques, the damping coefficient was distributed to several building models according to each method.

\section{Distributing the Damping Coefficient}

The damping coefficient is allocated to each structure using the different placement methods. To compare the different damper placement techniques, the total viscous damping coefficient added to the structure is constrained to be the same value for each method. As the placement of damping coefficients along a structure's height can affect the achieved damping ratio, the ratios will be approximate. It has been noted that the cost of a FVD is dependent on several parameters in addition to the damping coefficient, such as the maximum absolute damper force. However, taking the sum of damping coefficients is similar to taking the sum of peak damping forces in simple cases ${ }^{43}$. The required damper investment is examined in Section 7.2.2. The total viscous damping coefficient is widely used in literature to compare damper placement methods. An alternative basis for comparison, such as total retrofit cost, could also be considered. However, only approximations for damper costs are currently widely available and were considered too unreliable to be used in a robust comparison of damper placement methods. Section 9 examines this comparison method for illustrative purposes.

Two levels of total damping in the first mode were selected for this investigation: $15 \%$ and $30 \%$. These values were chosen to represent a smaller level frequently selected based on structural parameters $(15 \%)^{44}$ and a larger amount of damping (30\%). Practical considerations may sometimes prevent implementation of the higher level of damping considered here. If the maximum axial load in a column is increased, it must be accounted for in the retrofit design. 
The $C_{\text {total }}$ corresponding to each level of total damping was calculated using a uniform damping distribution and the energy method from Whittaker et al. ${ }^{45}$ modified to improve its accuracy (Equation 5), where $\zeta_{d}$ is the supplemental damping ratio, $T_{l}$ is the first period of the structure, $\theta_{j}$ is the angle of damper inclination at storey $j, m_{i}$ is each lumped mass, and $M_{1}^{p}$ is the modal mass participation factor of the first mode. The total damping coefficients for each considered building are provided in Table 3, where values are halved due to the use of 2D structural models.

$$
\zeta_{d}=\frac{T_{1} \sum_{j} C_{j} \cos ^{2} \theta_{j} \phi_{r j}^{2}}{4 \pi M_{1}^{p} \sum_{i} m_{i} \phi_{i}^{2}}
$$

Equation 5

Table 3: Total damping coefficients used in the comparison of damper placement methods

\begin{tabular}{crrr}
\hline Total Damping & \multicolumn{3}{c}{$C_{\text {total }}(\mathbf{N}$ s/mm $)$} \\
\cline { 2 - 4 } & $\mathbf{4 S}$ & $\mathbf{8 S}$ & $\mathbf{1 6 S}$ \\
\hline $15 \%$ & 10,107 & 36,412 & 76,865 \\
$30 \%$ & 25,267 & 91,030 & 192,163 \\
\hline
\end{tabular}

These values of $C_{\text {total }}$ were allocated to the OpenSees building models without any further analyses using the one-step placement methods: uniform damping, stiffness proportional damping, the SEM and the ESEM. The two iterative methods, the SSSA and the FSDA, require further analyses and are discussed below.

\subsection{Simplified Sequential Search Algorithm Iterations}

The SSSA attempts to place dampers sequentially where their effect will be maximized. The algorithm is subject to the assumption that the optimal storey to allocate a damper is the one that undergoes a maximum structural response during the ground motion. Location indices are calculated for each storey at the end of a time history analysis using one ground motion. As linear FVDs are velocity-dependent dampers, the location indices are given by peak interstorey velocity. The response of the bare frame is determined, and the first damper is allocated to the storey with the greatest location index. The damper properties are incorporated into the model and the process is repeated until all dampers have been placed.

The SSSA is a leading damper placement method and is extensively referenced in literature. The proposer recognized the need for a practical method that can improve seismic performance. However, assumptions and limitations are introduced as a result.

One limitation of the SSSA is that the resulting damper distribution is dependent on the ground motion record used to conduct the procedure. If multiple ground motion records are considered, it was found that the resulting damper distributions differed for each record. ${ }^{24}$ The SSSA requires engineering judgement to select a final damper distribution. To address this limitation, the seven ground motion records of the ULS suites with the smallest MSE with respect to the Eurocode 8 spectrum for each building were used to conduct the SSSA. Seven records were used according to Eurocode 8 recommended number of analyses for time history evaluations. ${ }^{11}$ The median damper coefficient values of each storey were then selected as the final SSSA distribution.

A second limitation of the SSSA is the assumption that the optimal damper location is the storey which experiences a peak structural response during the ground motion. This assumption was not completely justified by the original proposers; however it was later shown that the SSSA is a fixed-step coordinate descent type method i.e. that the SSSA is related to a class of optimization methods whose convergence properties have been formally proved under certain conditions. ${ }^{46}$ Interstorey velocity is a local parameter for each storey. The performance of each local parameter is not independent in a structure. Another limitation of the SSSA is that the method requires iteration, introducing a major resource demand (time and computational). Hwang et al. ${ }^{22}$ illustrated an additional limitation of the SSSA. In several case studies, it was found that the SSSA clustered dampers in a small number of storeys. Damper forces would therefore be concentrated in these storeys during an earthquake. This concentration could cause capacity problems in structural members adjacent to the dampers. However, a small number of dampers can also be an advantage as damper installation costs and disruption may be minimized. A final limitation is that no relation to the optimal seismic performance in terms of repair costs is made.

Time history analyses of the OpenSees models were conducted with all steel materials assigned elastic behavior for the SSSA iterations. The relative velocity of each floor was recorded in OpenSees using the node 
recorder (recorder Node ... vel). Interstorey velocity values could then be calculated and the absolute peak values identified. The number of dampers $\left(n_{d}\right)$, and therefore the number of iterations conducted, determine the value of the incremental damping coefficient $\left(c_{\text {incr }}=C_{\text {total }} / n_{d}\right)$. The number of dampers was selected to be equal to two times the number of storeys $\left(n_{d}=2 n\right)$; this number was proposed by Lopez Garcia and Soong ${ }^{24}$ as the optimal number of dampers for the SSSA.

An example of the iterative process of the SSSA is shown in Figure 3 for the eight-storey building with $30 \%$ total damping, where the peak interstorey velocities are shown for each iteration. The ground motion record used is Taiwan SMART1 1986. The dampers were placed in the following order of storeys: 6, 7, 6, 5, 4, 5, 4, 4, 7, 5, $3,6,3,1,2,1$. The final design reduces the peak interstorey velocity of all storeys and produces comparable peak values for all storeys. Figure 4 to 6 display the SSSA results for each of the seven ground motion records and all building models. The record sequence numbers (RSN) correspond to a specific earthquake and station. The RSN information is available in the Del Gobbo et al. ${ }^{8}$ study.

Figure $6 \mathrm{~b}$ reveals a concentration of dampers in one storey of the 16-storey structure when the SSSA is conducted using ground motion RSN 4207 (Niigata Japan 2004). The SSSA iteration process for the outlier is displayed in Figure 7. This outlier demonstrates the possible variation in results when conducting the SSSA, and the importance of using several ground motions with engineering judgement. The use of median $c_{j}$ values is less sensitive to outliers than the mean.

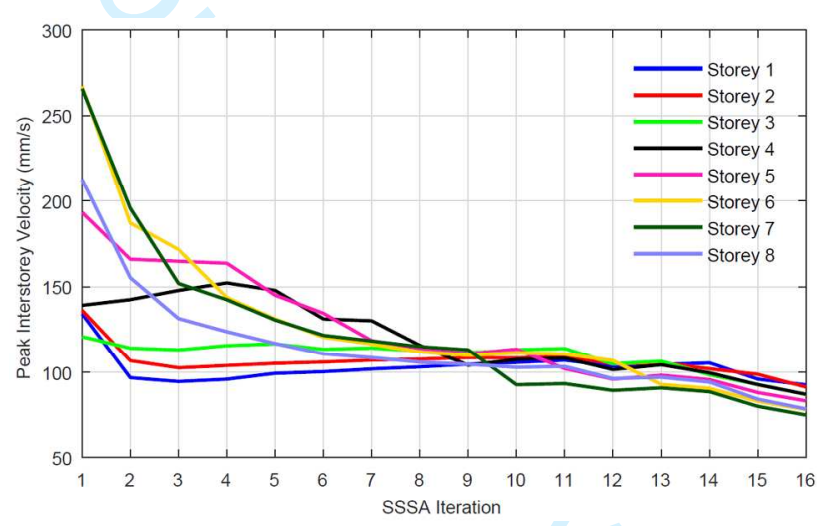

Figure 3: Peak interstorey velocity-SSSA iteration results for the eight-storey building with $30 \%$ damping. Taiwan SMART1 1986 ground motion

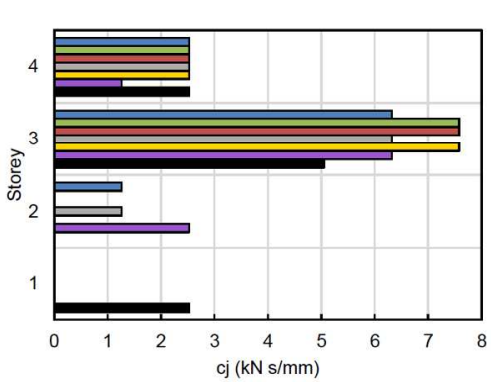

(a) 15\% total damping

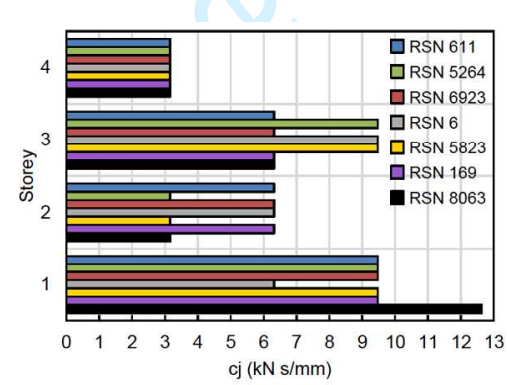

(b) $30 \%$ total damping

Figure 4: SSSA distributions for the four-storey building 


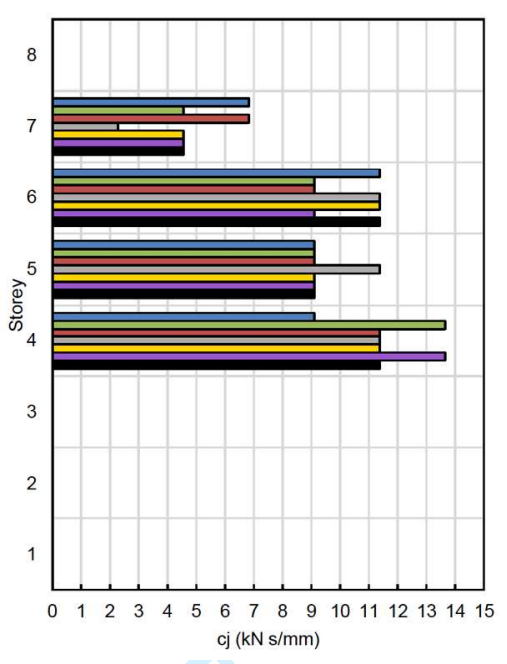

(a) $15 \%$ total damping

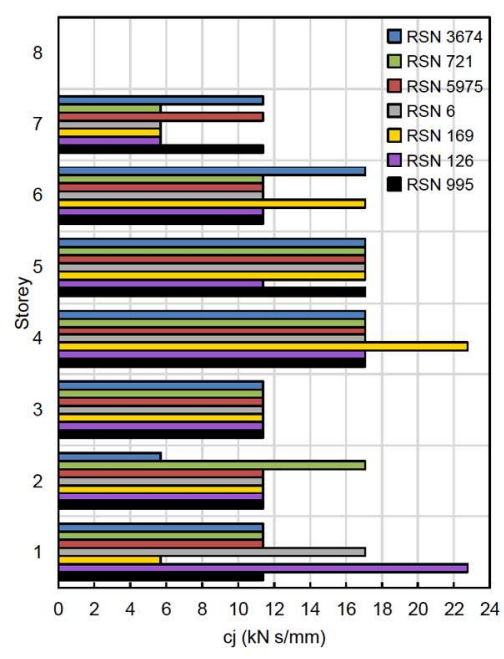

(b) $30 \%$ total damping

Figure 5: SSSA distributions for the eight-storey building

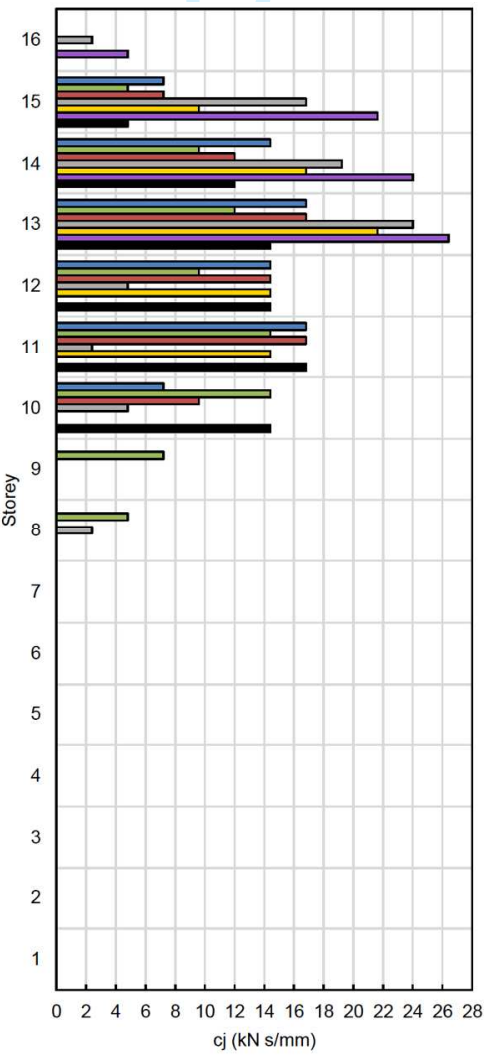

(a) $15 \%$ total damping

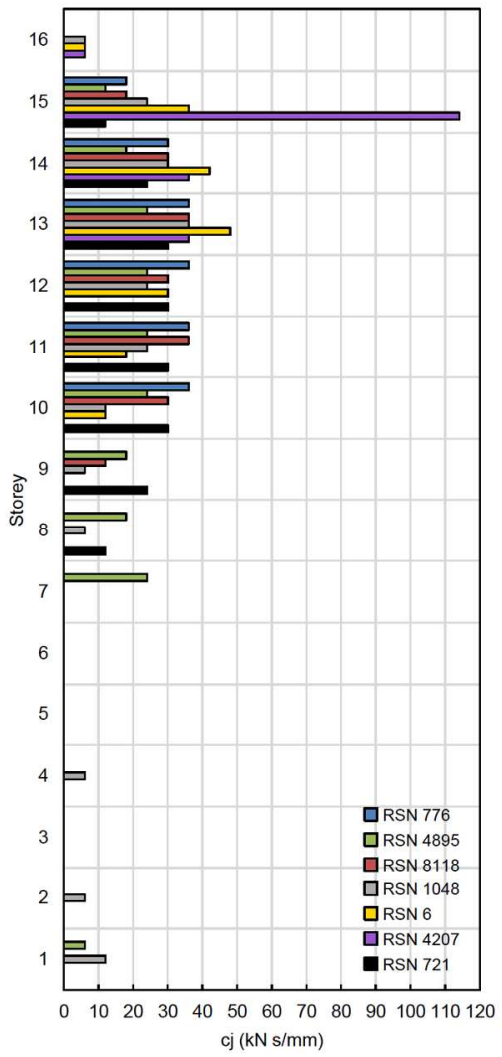

(b) $30 \%$ total damping

Figure 6: SSSA distributions for the 16-storey building 


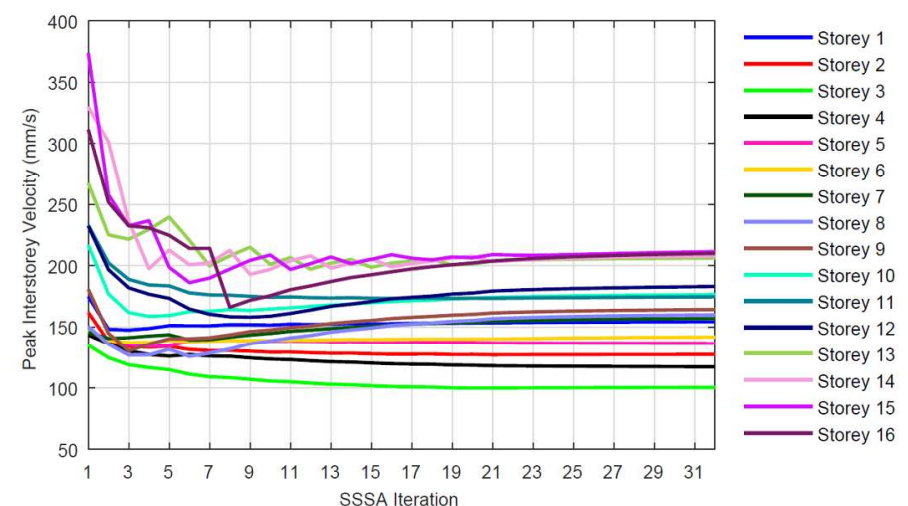

Figure 7: Peak interstorey velocity-SSSA iteration results for the 16-storey building with 30\% damping. RSN 4207 ground motion

\subsection{Fully Stressed Design Algorithm Iterations}

The FSDA is the second iterative damper placement method considered. The modified algorithm ${ }^{47}$ was used, which minimizes the maximum mean squared interstorey drift for a constrained amount of total added damping. The recurrence relationship of Equation 6 is used to allocate damping coefficients to each storey based on a performance index, where $c_{j}^{k}$ is the damping coefficient of the $j$ th-storey at iteration $k, p i_{j}^{k}$ is the performance index, and $q$ is a convergence parameter.

The maximum interstorey $\operatorname{drift}\left(d_{j}\right)$ normalized by the allowable interstorey $\operatorname{drift}\left(d_{a}\right)$ is the performance index for 2D linear models: $p i_{j}=\frac{d_{j}}{d_{a}}$ where $d_{j}=\max _{t}\left(d r i f t_{j}(t)\right)$. However, the modified algorithm is defined such that the allowable interstorey drift limit does not affect the final damper distribution if the value is equal for all the storeys. The recurrence relationship of the modified algorithm reduces to Equation 7, where $d_{a}$ is no longer present.

$$
\begin{aligned}
c_{j}^{k+1} & =c_{j}^{k}\left(p i_{j}^{k}\right)^{\frac{1}{q}} \frac{C_{\text {total }}}{\sum_{i} c_{i}^{k}\left(p i_{i}^{k}\right)^{\frac{1}{q}}} \\
c_{j}^{k+1} & =c_{j}^{k}\left(d_{j}^{k}\right)^{\frac{1}{q}} \frac{C_{\text {total }}}{\sum_{i} c_{i}^{k}\left(d_{i}^{k}\right)^{\frac{1}{q}}}
\end{aligned}
$$

Equation 6

Equation 7

The algorithm terminates once $c_{j}^{k+1} \approx c_{j}^{k}$ for two subsequent iterations. This was defined to be $\leq 5 \%$. A value of $q=0.5$ was used as suggested for linear problems by Levy and Lavan. ${ }^{26}$ The starting $c_{j}$ values were initialized using a uniform damping distribution. ${ }^{26}$ The FSDA is started with one "active" ground motion. The active ground motion is chosen for the linear problem based on the maximum spectral displacement at the first period of the structure for all records in the ground motion suite. The analysis and redesign procedure is carried out until the stopping criterion is reached. This is referred to as one run of the FSDA in this paper.

The design determined using the first run of the FSDA is then assessed by conducting time history analyses using all other ground motions in the suite of interest. If any ground motion in the inactive set produces a $\max _{j}\left(p i_{j}\right)$ that exceeds that of the active set, the inactive record with the largest $p i_{j}$ is added to the active set. A second run of the FSDA is performed, where the envelope of the active set $p i_{j}$ is used to determine the new $c_{j}$ values. The algorithm is complete once the stopping criterion of a run is reached and no additional records are added to the active set. Seven ground motion records with the smallest MSE with respect to the Eurocode 8 target spectrum were used to conduct the FSDA. These are the same suites of ground motions used for the SSSA.

A unique advantage of the FSDA is that the method allows a specified target performance level (interstorey drift in the linear 2D case) to be achieved. The majority of damper placement methods cannot be directly applied to reach a target performance limit. Another advantage of the FSDA is that it explicitly takes account of variability 
between earthquake records. The unmodified FSDA also allows a uniform distribution of interstorey drift to be achieved, however this is not the case for the modified FSDA.

A major limitation of the FSDA is the use of interstorey drift as the performance index. Accelerationsensitive nonstructural systems are ignored, and repair costs are not considered. The procedure is also iterative, and therefore can be time consuming and computationally intensive.

It was found that a maximum of one run was necessary for the four-storey building, while the eight- and 16-storey buildings required two runs. An example of the FSDA iterative process is provided in Figure 8 for the four-storey building with $30 \%$ total damping. The interstorey drift and damping coefficient values per storey at each iteration are provided. The stopping criterion of $c_{j}$ convergence was reached at 19 iterations. As all other ground motions in the suite of seven records did not exceed the performance index of the active set, only one run was required. An example of the FSDA iterative process when two runs are required is provided in Figure 9 for the eight-storey building with $30 \%$ total damping. The interstorey drift and damping coefficient values per storey at each iteration are shown. The stopping criterion of $c_{j}$ convergence was reached after only five iterations in the second run.

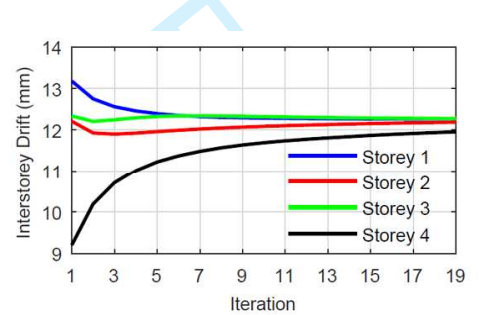

(a) interstorey drift

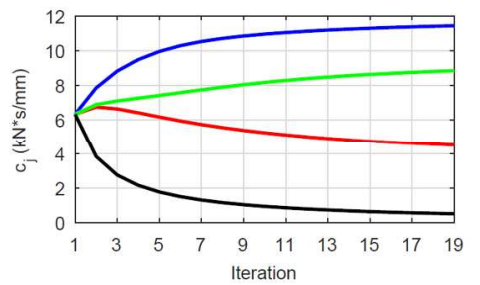

(b) $c_{j}$

Figure 8: Iterations of the FSDA for the four-storey building with $30 \%$ total damping
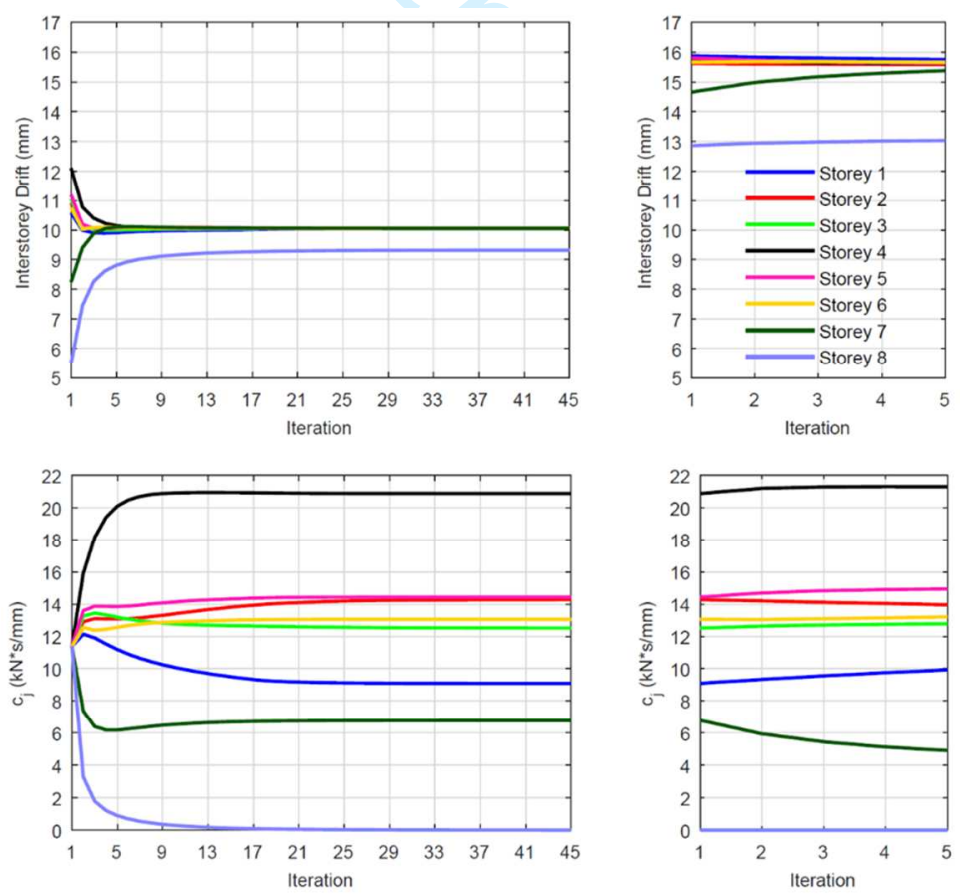

Figure 9: Iterations of the FSDA for the eight-storey building with $30 \%$ total damping (a) interstorey drift, run 1 (b) interstorey drift, run 2 (c) $c_{j}$, run 1 (d) $c_{j}$, run 2

\subsection{Analysis Time Required for the Iterative Methods}

Both the FSDA and the SSSA are iterative procedures. These methods can be time consuming and computationally expensive if many iterations must be performed or if complex models are used. The analysis time required to perform the damper placement methods is listed in Table 4 . The average time for the $15 \%$ and $30 \%$ total damping 
models is provided. Analysis was carried out on a Windows 7 desktop with an Intel Core i7-4770 CPU, 16GB RAM, and a 7200RPM hard drive. Both methods require a reasonable amount computational time and could be implemented in practice. This is unlikely to be prohibitive in the context of achieving significant performance improvements in major buildings. The FSDA outperforms the SSSA for the eight- and 16-storey models with regards to the required analysis time, however the differences are minor.

Table 4: Average time required to implement the iterative damper placement methods

\begin{tabular}{lrrr}
\hline Method & Four-Storey & Eight-Storey & 16-Storey \\
\hline SSSA & $6 \mathrm{~min}$ & $27 \mathrm{~min}$ & $105 \mathrm{~min}$ \\
FSDA & $5 \mathrm{~min}$ & $12 \mathrm{~min}$ & $61 \mathrm{~min}$ \\
\hline
\end{tabular}

\section{Comparison of Damping Coefficient Distributions}

The damper coefficient distributions resulting from each considered damper placement method are compared in Figure 10 to 12, where $K$ refers to stiffness proportional damping and Uni refers to uniform damping.
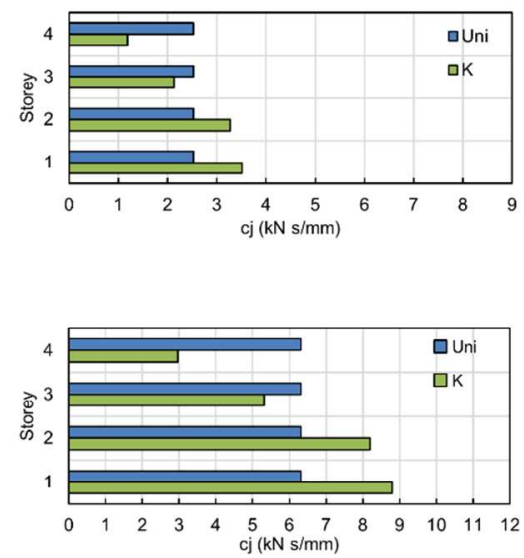

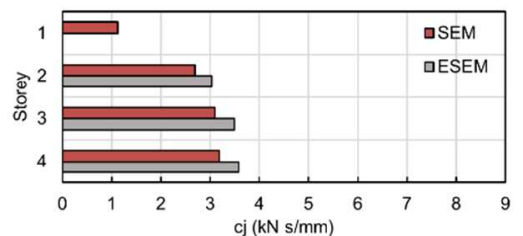

(a) $15 \%$ total damping

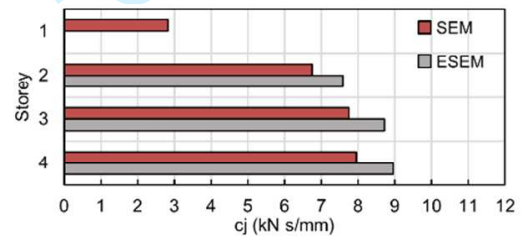

(b) $30 \%$ total damping
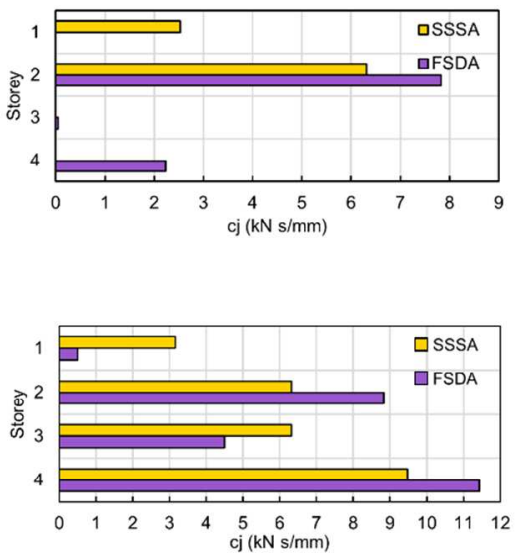

Figure 10: Damping coefficient distributions for the four-storey building resulting from several damper placement methods
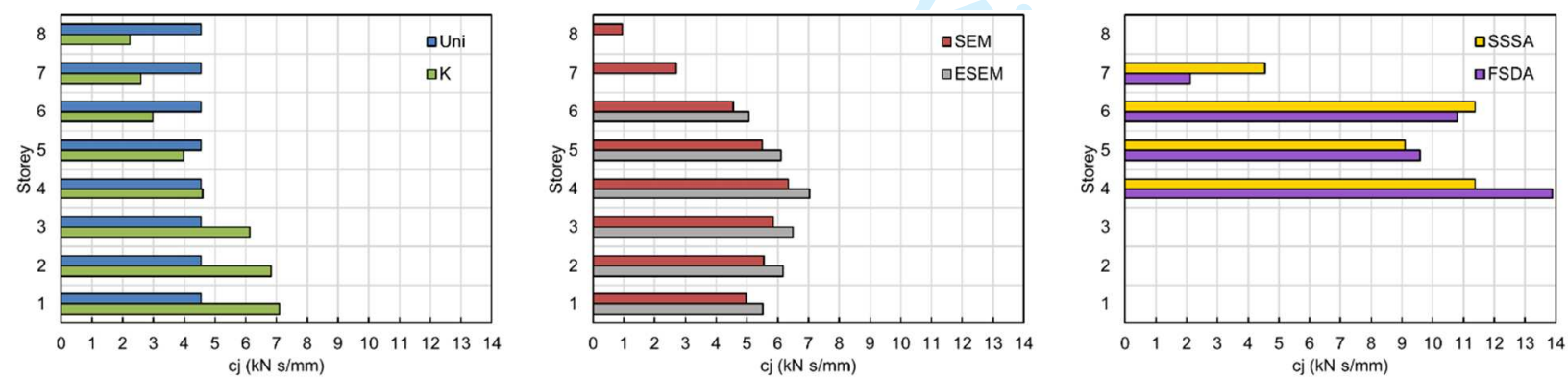

(a) $15 \%$ total damping
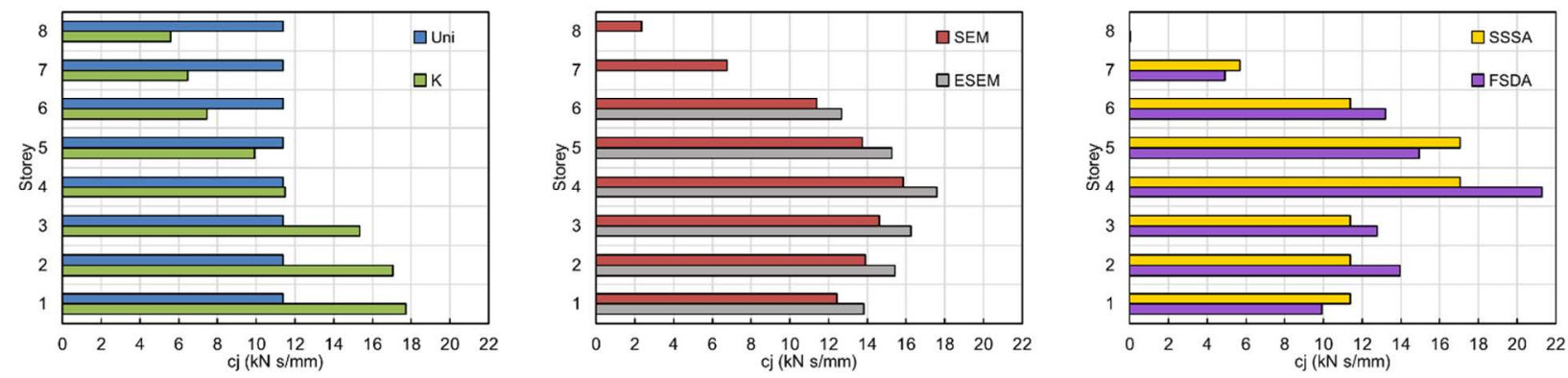

(b) $30 \%$ total damping 
Figure 11: Damping coefficient distributions for the eight-storey building resulting from several damper placement methods
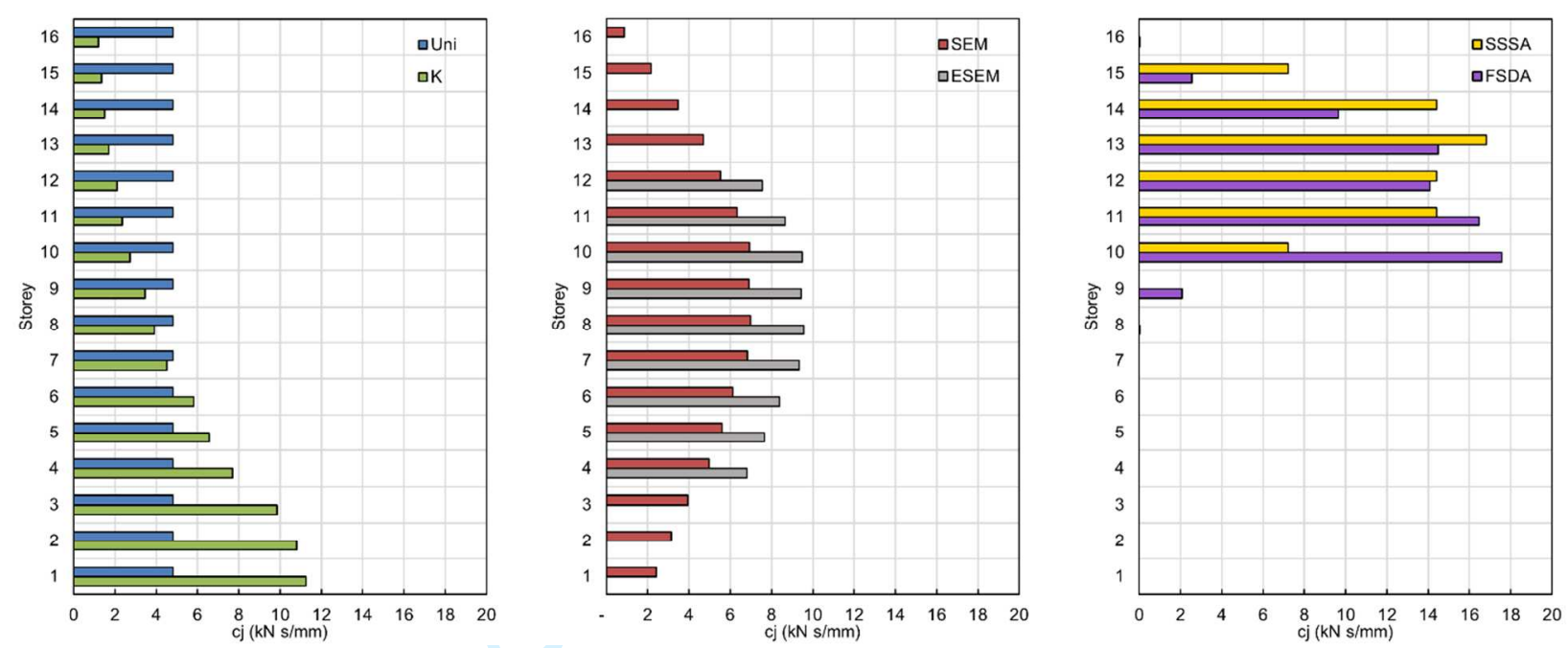

(a) $15 \%$ total damping
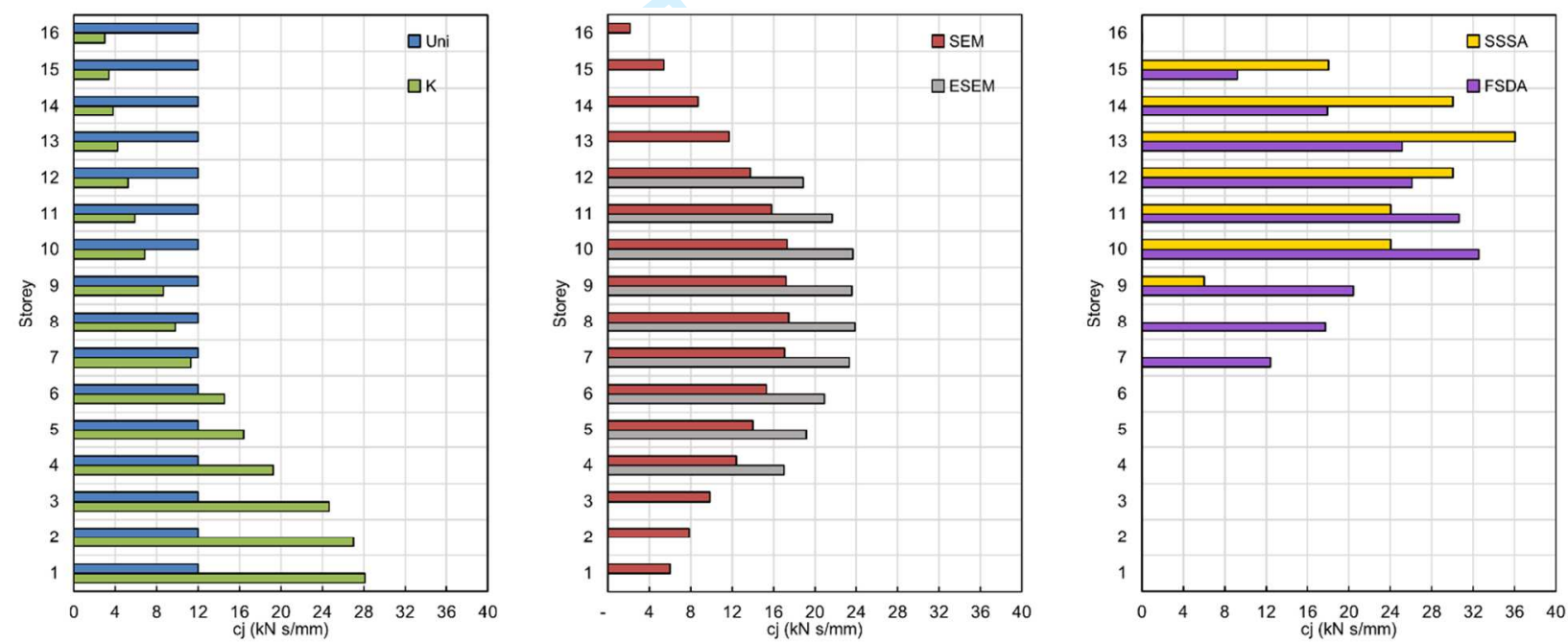

(b) $30 \%$ total damping

Figure 12: Damping coefficient distributions for the 16-storey building resulting from several damper placement methods

The damper distributions exhibit similar results for the four- and eight-storey structures. The non-iterative methods generally exhibit an even distribution of dampers, excluding the top storeys which are allocated minimal damping. The SSSA and the FSDA concentrate dampers in the middle storeys, although this concentration is significantly more pronounced for $15 \%$ than $30 \%$ total damping. The concentration of dampers is reduced for the $30 \%$ case as enough supplemental damping is provided to sufficiently improve the iterative performance indices of the "weak" storeys. Dampers can then be allocated to additional storeys.

The damping distributions of the 16-storey building have some variation with respect to the patterns of the four- and eight-storey buildings. The SEM and the ESEM places dampers in the middle storeys, with reduced values of damping in the lower and upper storeys. The SSSA and the FSDA concentrate dampers in the middle to upper storeys, and this concentration is pronounced for both considered levels of damping.

\section{Time History Analyses}


Nonlinear time history analyses of each structural model and damper placement distribution were performed in OpenSees using the ULS and SLS ground motion suites. Peak EDPs from the time history analyses are used to characterize demands on structural and nonstructural systems. Section 7.1 compares the EDP results for each damper placement method. Section 7.2 examines the damper forces generated for the different placement methods. The damper forces are used to measure the efficiency of damper placement and estimate the required damper investment.

\subsection{Engineering Demand Parameter Results}

Effects of the damper placement methods on seismic response were observed by comparing the EDP results of the FVD designs. The peak EDPs were also used as inputs for the FEMA P-58 seismic performance assessment. ${ }^{7}$ The mean of the peak absolute floor accelerations and interstorey drifts per building level are shown in Figure 13 and 14 for the FVD buildings with $15 \%$ and $30 \%$ total damping, respectively. The peak absolute velocity results are omitted, as the FVDs affect relative velocities but their impact on absolute velocities is modest. As expected, no single damper placement method produces optimal results for both interstorey drifts and accelerations.
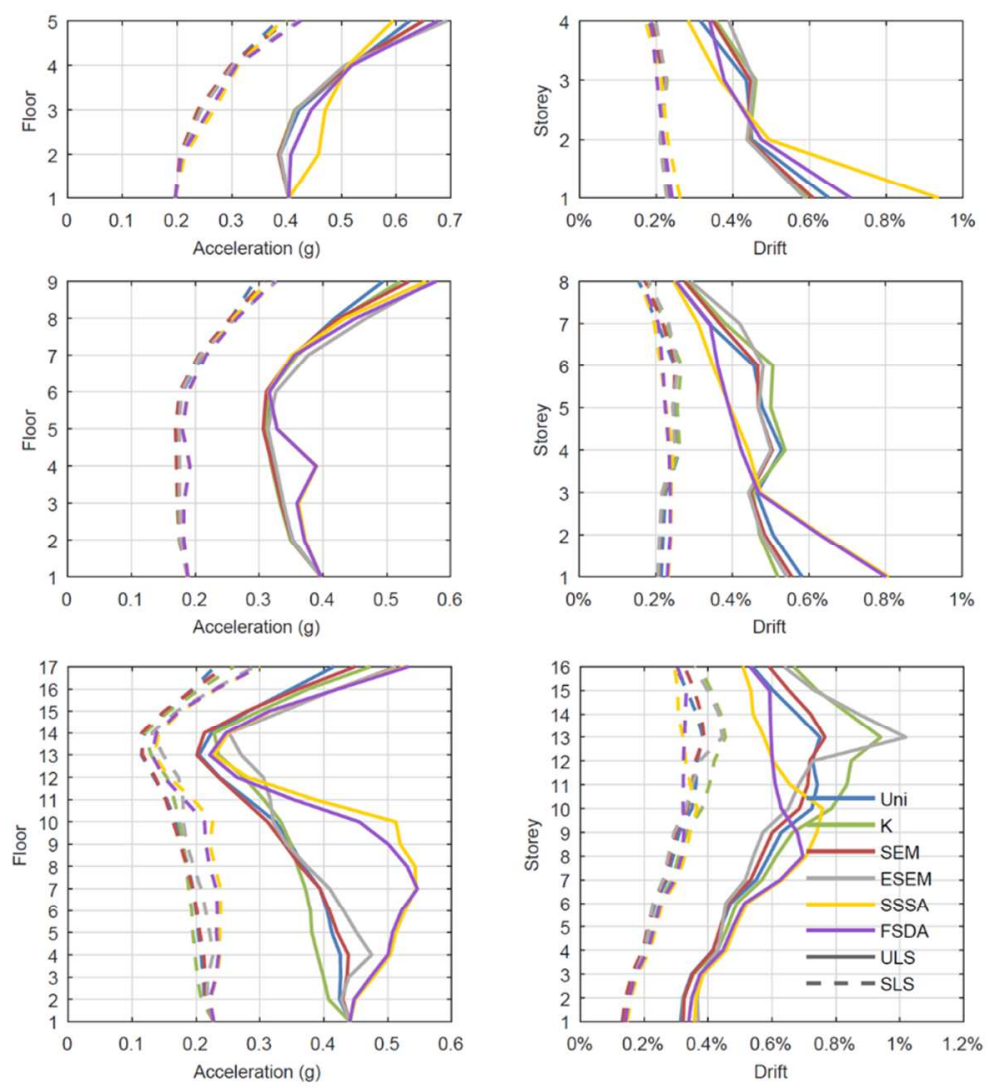

Figure 13: Comparison of the mean peak EDPs from the different damper placement methods, $15 \%$ total damping (a) Four-storey absolute acceleration (b) Four-storey interstorey drift (c) Eight-storey absolute acceleration (d) Eight-storey interstorey drift (e) 16-storey absolute acceleration (f) 16-storey interstorey drift 

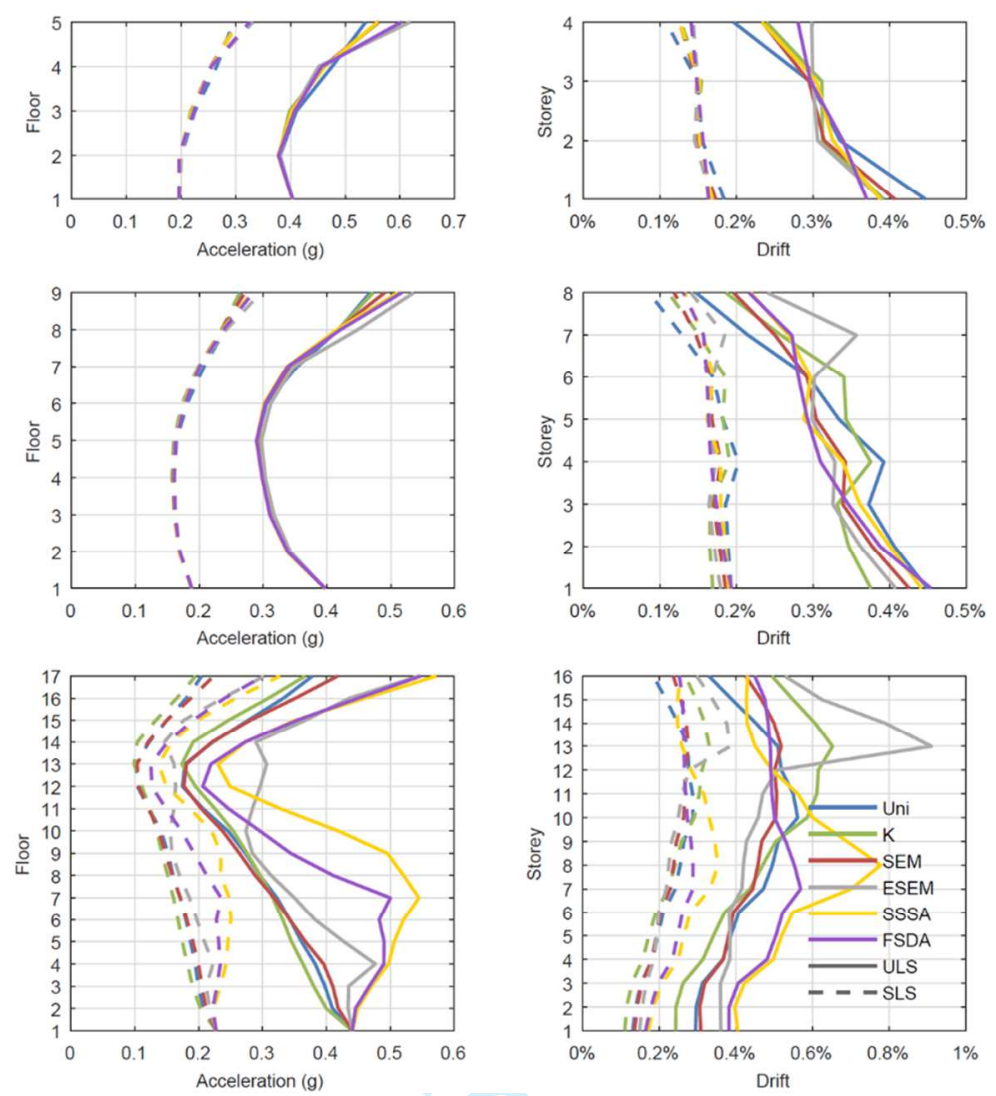

Figure 14: Comparison of the mean peak EDPs from the different damper placement methods, $30 \%$ total damping (a) Four-storey absolute acceleration (b) Four-storey interstorey drift (c) Eight-storey absolute acceleration (d) Eight-storey interstorey drift (e) 16-storey absolute acceleration (f) 16-storey interstorey drift

The EDPs for 15\% total damping are shown in Figure 13. The differences in the SLS results for all placement methods are minimal. The ULS accelerations display a similar pattern for all three building heights: the SSSA and the FSDA have larger acceleration values at the floors below the concentration of FVDs with respect to the non-iterative methods. The iterative methods have poor ULS interstorey drift control at the lower storeys when compared to the non-iterative methods; the iterative methods do not allocate significant damping coefficients to these lower storeys. Improved interstorey drift control is achieved by the iterative methods at the upper storeys where FVDs are concentrated.

Stiffness proportional damping and the ESEM exhibit a large ULS interstorey drift concentration at storey 13 of the 16-storey building. This reveals a limitation of the damper placement methods, as stiffness discontinuities, weak storeys or other structural shortcomings may not be addressed.

The EDPs for 30\% total damping are shown in Figure 14. The difference in the acceleration results between all placement methods are negligible for the four- and eight-storey structures. The interstorey drifts of the four- and eight-storey buildings do not display any significant differences among the different damper distributions.

The accelerations of the 16-storey building vary greatly among the damper placement methods. As in the case of $15 \%$ damping, the methods that concentrate dampers in only a few storeys (the SSSA, the FSDA and the ESEM) exhibit large accelerations with respect to uniform damping at the storeys below the concentration of dampers. The ULS interstorey drifts of the 16-storey building with $30 \%$ damping exhibit the same trends as in the $15 \%$ case. The iterative methods generally have poor interstorey drift control at the lower storeys without FVDs.

\subsection{Damper Force}

Examining damper forces generated by the different damper distributions can also help to distinguish between the placement methods. Damper forces can be used to measure the efficiency of damper placement and estimate the 
required damper investment. The damper forces generated during the time history analyses were recorded in OpenSees using the command recorder Element with the argument of localForce. The maximum absolute ULS damper forces are of interest, as they will govern the effects on adjacent structural members as well as the required damper investment. ${ }^{25,43,48}$

The maximum absolute force in each damper was determined for every ground motion analysis. The mean of these peak values per damper were then calculated. The force results of the eight-storey building, representative of the four- and 16-storey results, are provided in Figure 15. The FSDA, the SSSA and the ESEM have concentrations of damper forces, as these methods concentrate dampers in a small number of storeys. The stiffness proportional distribution also produces large damper forces in the first several storeys of the 16-storey building. These large forces must be considered during structural retrofit and local strengthening of structural members may be required.

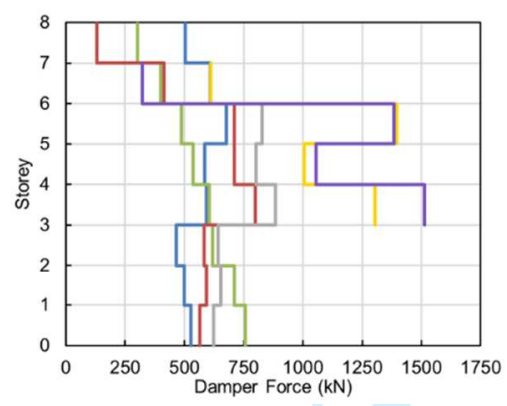

(a) $15 \%$ Damping

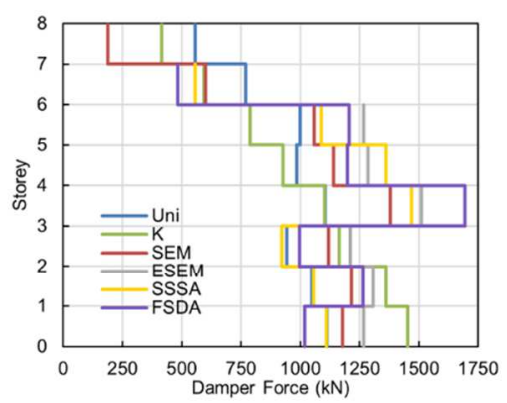

(b) $30 \%$ Damping

Figure 15: Eight-storey building, mean peak damper forces per damper for different placement methods

\subsubsection{Efficiency Ratio}

Consistency between the distribution of maximum absolute damper forces and damper coefficients over the building height was proposed by Hwang et al. ${ }^{22}$ as a measure of damper placement efficiency. If the distribution of the maximum damper forces is consistent with the distribution of damping coefficients, the damping coefficients can be thought to efficiently engage in energy dissipation. ${ }^{22,25}$ This measure of damper efficiency is examined due to its frequency in relevant literature, however the measure was not presented with robust justification by the original proposers.

As linear FVDs are used in this study, the ratio of maximum absolute damper force to damping coefficient is the peak interstorey velocity (assuming vertical movements are minor in comparison to the horizontal motion). The SSSA should therefore produce approximately uniform efficiency ratios. Figure 16 displays the ratio of the maximum damper forces and damper coefficient ( $\mathrm{F} / \mathrm{C}$ ratio) per storey for each damper placement method and level of total damping considered.

The difference between the maximum and minimum $\mathrm{F} / \mathrm{C}$ ratio increases as the total building height increases. Uniform damping produces ratios less than, and therefore less efficient than, those of stiffness proportional damping and the SEM at higher storeys as expected. The SEM and the ESEM appear to produce the most favorable $\mathrm{F} / \mathrm{C}$ ratios considering both levels of damping and all three building heights. However, the difference in $\mathrm{F} / \mathrm{C}$ ratios between the various placement methods is minor and should not be overstated.

\subsubsection{Damper Cost}

The required damper investment should be considered when evaluating FVD placement methods. Damper costs for each placement method were determined using the Gidaris and Taflanidis ${ }^{48}$ cost equation for commercially available dampers (Equation 8), where $\operatorname{Cost}_{i}$ is the cost of damper $i$ in dollars and $f_{\text {max }, i}$ is the maximum absolute force capacity of damper $i$ in $\mathrm{kN}$. It is recognized that the damper cost formula is an approximation and does not capture additional costs such as frame strengthening or lost rentable space.

$$
\operatorname{Cost}_{\mathrm{i}}=96.88\left(f_{\max , i}\right)^{0.607}
$$



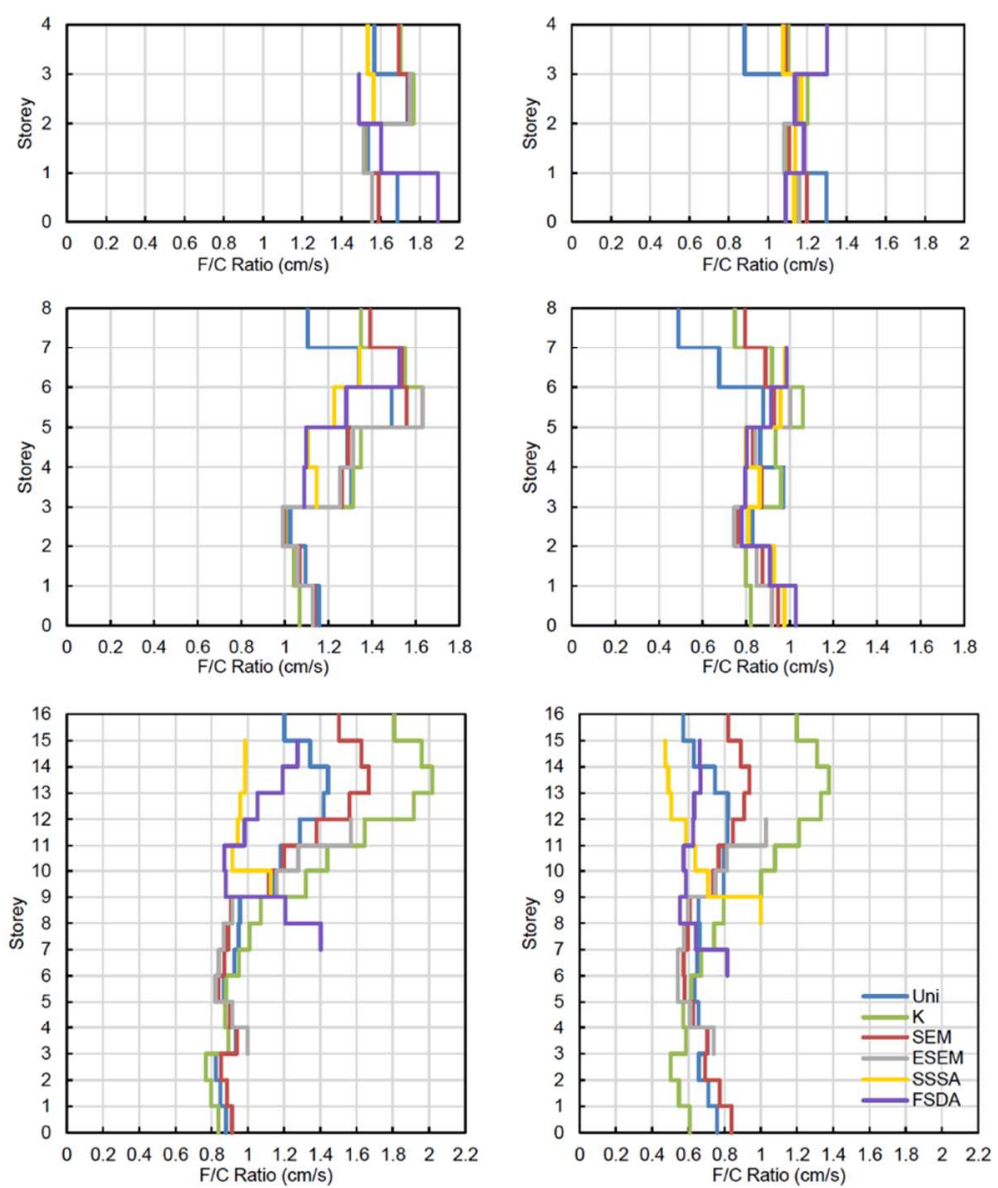

Figure 16: Ratio of the maximum damper forces and damper coefficient per storey for different placement (a) Fourstorey 15\% damping (b) Four-storey 30\% damping (c) Eight-storey 15\% damping (d) Eight-storey 30\% damping (e) 16-storey $15 \%$ damping (f) 16-storey $30 \%$ damping

The total damper investment for each damper placement method was determined based on the maximum absolute ULS forces of each damper considering all time history analyses. The damper costs for each placement method and building case are listed in Table 5, where $\Delta_{\text {cost,max }}$ is the range in investment.

Table 5: Damper investment for each placement method $(\$ 1,000)$

\begin{tabular}{|c|c|c|c|c|c|c|}
\hline \multirow[t]{2}{*}{ Method } & \multicolumn{3}{|c|}{ 15\% Damping } & \multicolumn{3}{|c|}{ 30\% Damping } \\
\hline & $4 S$ & $8 \mathrm{~S}$ & $16 S$ & $4 S$ & $8 \mathrm{~S}$ & $16 \mathrm{~S}$ \\
\hline Uniform & 72 & 172 & 384 & 100 & 233 & 499 \\
\hline Stiffness & 71 & 171 & 374 & 98 & 236 & 513 \\
\hline SEM & 71 & 170 & 377 & 98 & 234 & 494 \\
\hline ESEM & 64 & 154 & 292 & 89 & 215 & 375 \\
\hline SSSA & 46 & 119 & 200 & 98 & 221 & 256 \\
\hline FSDA & 54 & 115 & 218 & 92 & 225 & 332 \\
\hline$\Delta_{\text {cost }, \max }$ & 26 & 56 & 184 & 11 & 21 & 257 \\
\hline
\end{tabular}

The iterative methods generally produce the minimum damper cost. The damper investment decreases by as much as $48 \%$ with respect to the maximum value. The ESEM also produces a reduction in cost to a lesser extent when considering the other non-iterative damper placement methods. The range in damper cost is greater for the larger buildings. While the relative damper costs demonstrate significant variations, the actual dollar values must be considered to evaluate the magnitude of cost differences with respect to the total building cost. All damper costs are less than $3 \%$ of the total building costs (Table 6), established in the Del Gobbo et al. study ${ }^{8}$ using the RSMeans square foot cost estimator. ${ }^{49}$ Values of $\Delta_{\text {cost,max }}$ are sufficiently small to be considered negligible for the four- and 
eight-storey structures. The 16-storey structure is associated with more substantial ranges of required damper investment. The variation in damper costs for the different 16 -storey placement methods may be significant depending on the corresponding changes in earthquake repair costs.

Table 6: Estimated Cost of Buildings

\begin{tabular}{ll}
\hline Building & Cost \\
\hline $4 \mathrm{~S}$ & $\$ 3.8 \mathrm{M}$ \\
$8 \mathrm{~S}$ & $\$ 8.6 \mathrm{M}$ \\
$16 \mathrm{~S}$ & $\$ 18.2 \mathrm{M}$ \\
\hline
\end{tabular}

\section{FEMA P-58 Assessments}

The FEMA P-58 performance assessment procedure was used to evaluate seismic performance in terms of repair costs. The use of repair costs is an appropriate measure of total-building seismic performance that avoids the limitations of structural parameters and damage indices. ${ }^{8}$ This evaluation enables the various damper placement methods to be compared considering total-building seismic performance.
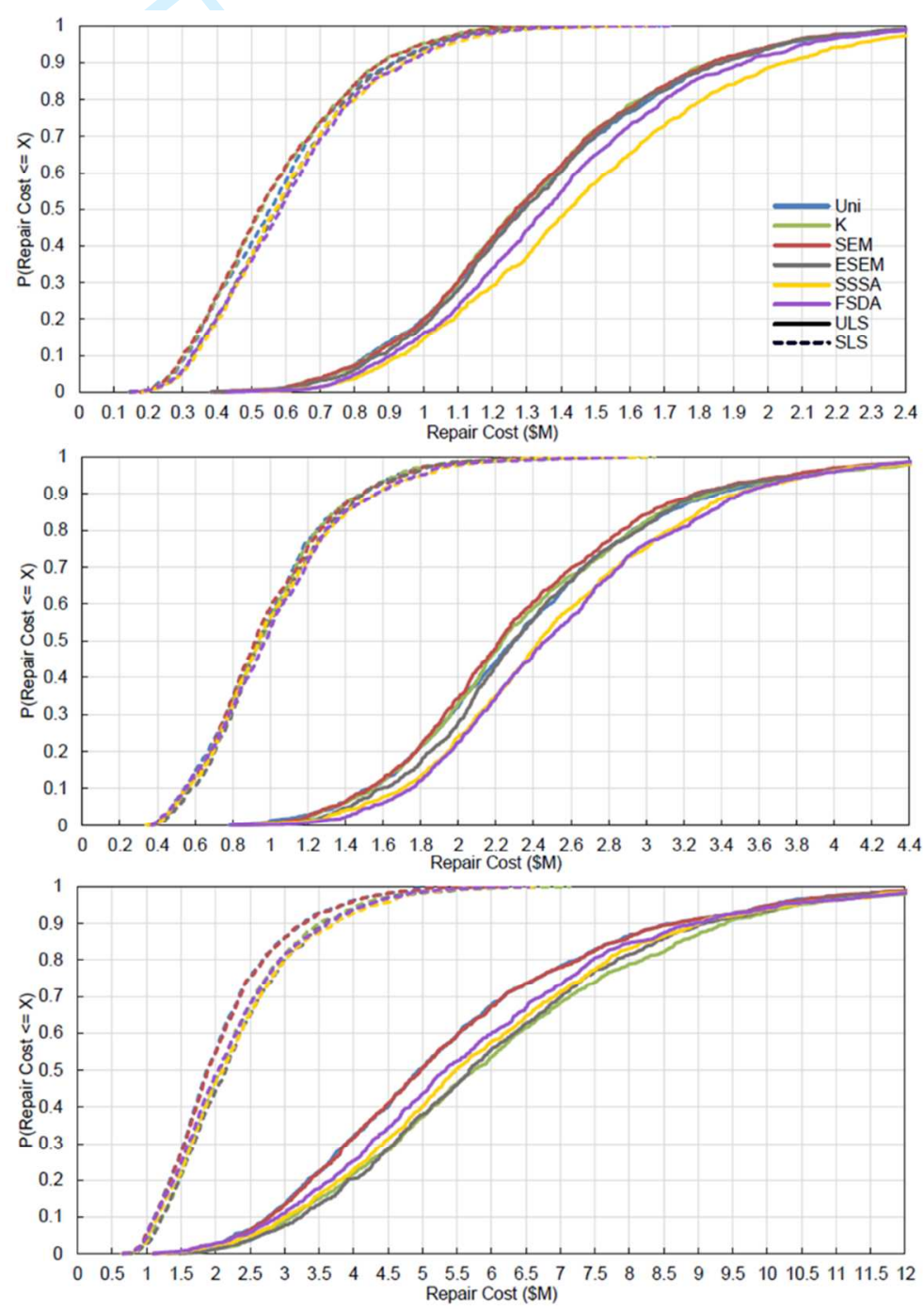

Figure 17: Cumulative distribution functions of total repair costs with $15 \%$ total damping (a) Four-storey (b) Eightstorey (c) 16-storey 
The FEMA P-58 intensity-based nonlinear performance assessment procedure was used. Each building component susceptible to damage during earthquakes is representing using fragility and repair cost functions. Structural and nonstructural components are considered. Peak EDPs from nonlinear time history analyses are used with fragility functions to determine probable damage states for the components. Repair cost functions then estimate the losses in dollars for each damage state. The FEMA P-58 critical fragility information used in this paper was the same as that provided by the Del Gobbo t $_{\text {al. }}{ }^{8}$ study. Structural fragility groups and quantities were determined by the structural design. Nonstructural fragility groups and quantities were estimated using the median commercial office building quantities from the Normative Quantity Estimation Tool. ${ }^{7}$ Robust equipment anchorage and seismic design category $\mathrm{D}$ for buildings with stringent seismic design were assumed to avoid overestimating repair costs.

Cumulative distribution functions of the ULS and SLS total repair costs are shown in Figure 17 and 18 for $15 \%$ and $30 \%$ total damping, respectively. Direct repair costs in 2011 US dollars resulting from damage to building assets are calculated, while indirect costs due to building downtime are out of scope.
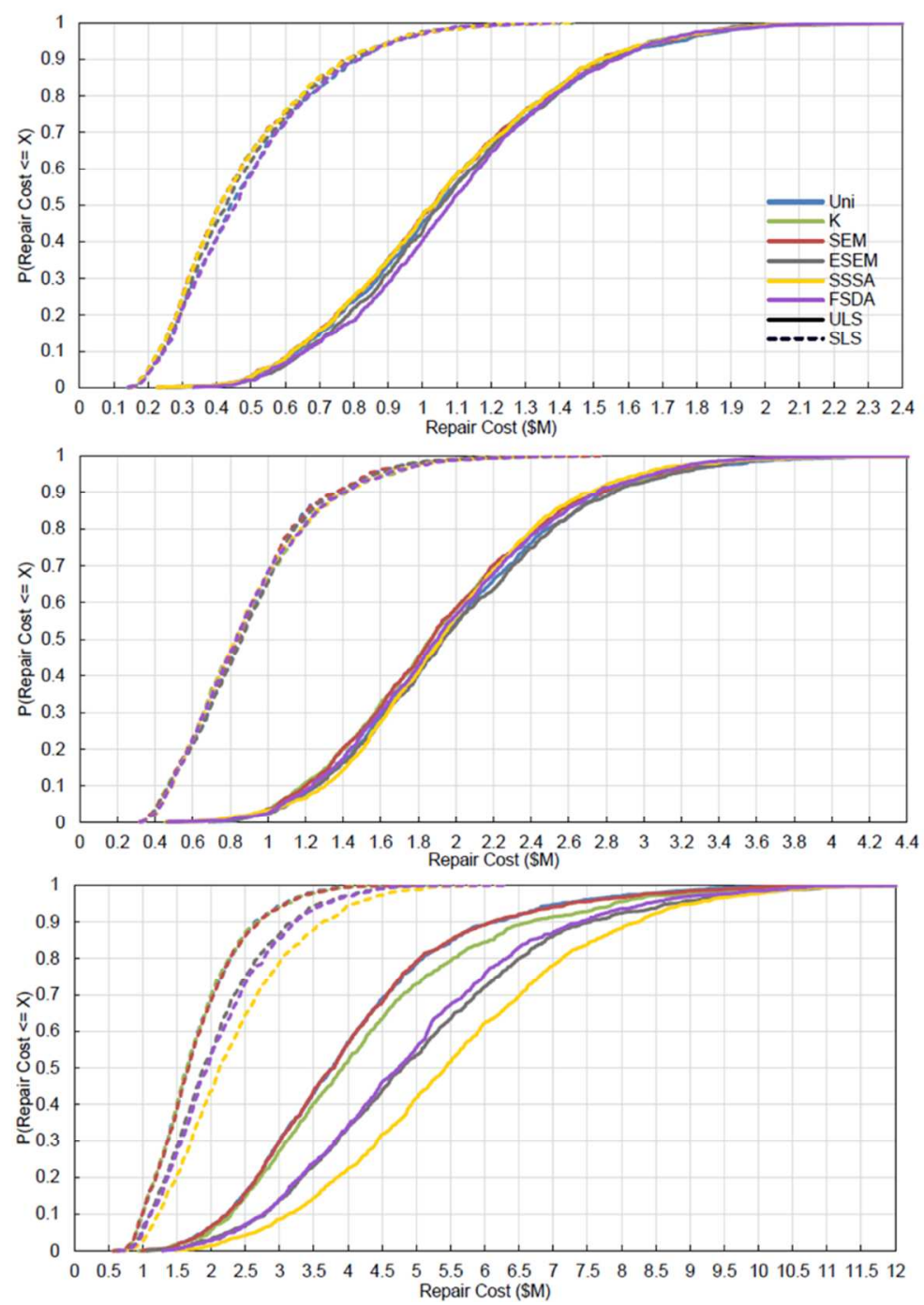

Figure 18: Cumulative distribution functions of total repair costs with $30 \%$ total damping (a) Four-storey (b) Eightstorey (c) 16-storey

The effect of increasing the total level of damping from $15 \%$ to $30 \%$ on estimated repair costs was examined, as damage reductions may be offset to some extent by the additional upfront FVD expenditure. The range of median and 90th percentile ULS repair costs for each building are provided in Table 7, along with the maximum 
damper investment for comparison. It was found that the additional reductions in repair cost from increasing the damping to $30 \%$ offset the increases in the maximum damper costs.

Table 7: Total ULS repair costs (\$M) for the different damper placement methods

\begin{tabular}{lrrrr}
\hline Building & Damping & Median Damage & 90 $^{\text {th }}$ Percentile Damage & Max FVD Cost \\
\hline 4-Storey & $15 \%$ & $1.3-1.4$ & $1.8-2.1$ & 0.1 \\
& $30 \%$ & $1.0-1.1$ & $1.5-1.6$ & 0.1 \\
8-Storey & $15 \%$ & $2.2-2.5$ & $3.3-3.5$ & 0.2 \\
& $30 \%$ & 1.9 & $2.7-2.8$ & 0.2 \\
16-Storey & $15 \%$ & $4.9-5.7$ & $8.7-9.4$ & 0.4 \\
& $30 \%$ & $3.8-5.4$ & $6.1-8.2$ & 0.5 \\
\hline
\end{tabular}

The SLS total cost distributions for the buildings with 15\% total damping (shown in Figure 17) do not significantly vary between the different damper placement methods. In contrast to the SLS results, the ULS total costs for $15 \%$ damping differ among the various placement methods. The SEM and uniform damper placement generally produce smaller repair costs than the other methods, while the iterative approaches (the SSSA and the FSDA) generally result in larger repair costs (the least favorable costs for the four- and eight-storey buildings).

For $30 \%$ total damping, the total repair cost distributions of the four- and eight-storey buildings do not differ for each damper placement method (refer to Figure 18). This holds true for both the ULS and the SLS results. For the 16-storey buildings, the earthquake damage of each placement method exhibits the same relative performance for both the ULS and the SLS. The SSSA results in significantly larger repair costs than any other method. The cost distributions for the FSDA and the ESEM are between those of the SSSA and the remaining noniterative methods. The concentration of dampers in a small number of storeys encouraged by the SSSA, the FSDA, and the ESEM has an overall negative effect on total-building seismic performance. The SEM and uniform damping produce the smallest, and therefore most favorable, total repair costs.

Reviewing the cumulative distribution functions of the total repair costs and the relative performance of each damper placement method reveals interesting results. The findings are summarized below and are limited to linear FVDs:

1. The iterative methods do not improve seismic performance.

2. The SEM, and notably the simplest method of uniform damping, generally produce repair costs that are more favorable than, or equal to, the other damper placement methods.

Although the iterative methods attempt to optimize seismic performance, the resulting total repair costs are not reduced with respect to the other damper placement methods. The iterative methods are superficially appealing, as the required investment in dampers is less than other methods. They also purport to optimize a representative measure of seismic performance. However, the iterative methods often produced the least favorable repair cost distributions. This is a result of the iterative methods optimizing parameters other than repair costs. These methods that purport to optimize seismic performance do not achieve that objective for total-building performance. Optimizing for a single parameter such as interstorey drift may worsen another parameter such as floor acceleration that also has a significant impact on earthquake damage and repair cost. The methods also optimize a local parameter (interstorey drift or velocity of each storey) assuming that the performance of each local parameter is independent. In contrast, the placement of a FVD in one storey will change the performance of additional storeys. Further complexities are introduced by the total repair cost being dependent on each individual building level. The concentration of dampers in a small number of storeys encouraged by the SSSA, the FSDA, and the ESEM has an overall negative effect on total-building seismic performance. The SEM and uniform damping produce the smallest ULS repair costs for the three structures with $15 \%$ total damping and the 16 -storey building with $30 \%$ damping.

3. It appears unlikely that large shifts in total repair cost cumulative distribution functions can be achieved using an "optimal" damper placement method for low- and mid-rise buildings. Repair cost functions are more sensitive to the level of total damping than to the damper placement method used. Damper placement optimization may be more successful for taller buildings.

The results of this study revealed that the costs functions are more sensitive to the level of total damping than to the damper placement method used. Variations in the total repair cost functions between the different methods should 
not be overstated, as the achieved changes in cost are comparable to the FEMA P-58 sensitivity to modelling assumptions as determined by Del Gobbo et al. ${ }^{8}$. At the higher level of damping, the four- and eight-storey ULS costs did not vary among the different damper distributions. However, the repair cost distributions of the 16-storey building displayed significant variations among the different damper distributions. It is possible that damper placement optimization may be more effective for high-rise structures.

\section{Upfront Damper Cost as a Basis for Damper Placement Comparison}

The upfront investment in FVDs is a valuable alternative basis for the comparison of damper placement methods. Although the damper costs presented in Table 5 do not consider additional costs due to installation and disruption, and cost factors such as the height at which the dampers are installed, these costs were used as a proof of concept.

It can be seen in Table 5 that the damper costs of the uniform, stiffness proportional, and SEM distributions at $15 \%$ target damping are similar in value to the damper costs of the ESEM, SSSA and FSDA at $30 \%$ target damping for the 16-storey building. One could feasible adopt any of these methods with the same upfront cost. The four- and eight-storey buildings damper costs do not exhibit this cost attribute. As a result, upfront damper cost was used to compare damper placement methods for the 16-storey building. The cumulative distribution functions of the ULS and SLS total repair costs for the 16-storey building with similar upfront damper costs are shown in Figure 19.

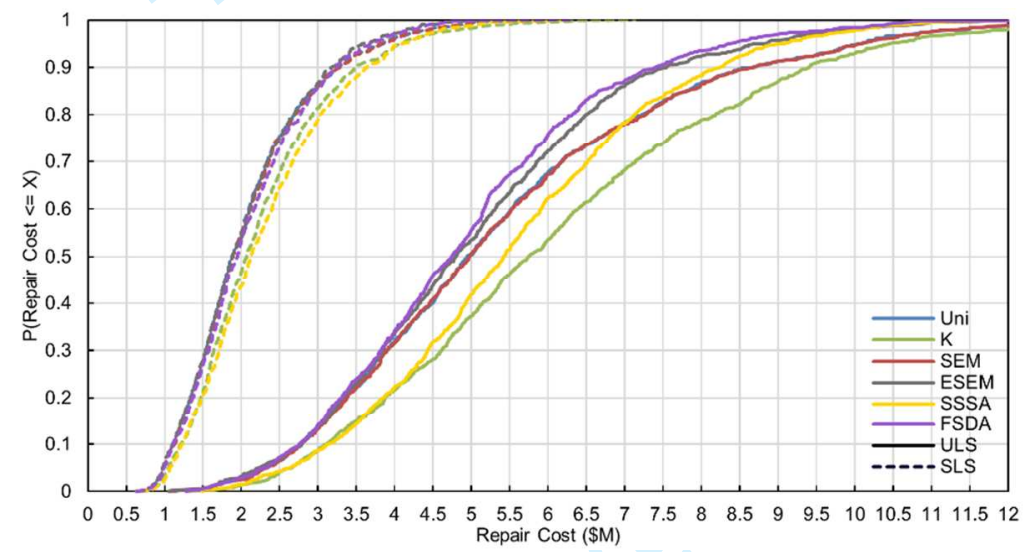

Figure 19: Cumulative distribution functions of total repair costs with compare damper costs, 16-storey building. Uniform, stiffness proportional and SEM distributions for 15\% target total damping. ESEM, SSSA and FSDA distributions for $30 \%$ target total damping.

Reviewing the relative performance of each damper placement method reveals that the SSSA generally does not improve performance in comparison to uniform damping and the SEM. This coincides with comparison of methods using the total damping coefficient. The ESEM and the FSDA produce favorable relative results. This result contradicts the findings of the placement comparison using total damping coefficient as a basis. These results demonstrate an advantage of the FSDA. The unmodified method uses a fully stressed procedure to achieve a desired performance and does not limit the total damping coefficient added. For the 16-storey building, the FSDA results in nearly double the total added damping coefficient to the structure. These results also demonstrate the influence of the comparison constraint on the relative performance of each damper placement method. However, it must be emphasized that the damper placement comparison based on upfront damper cost is for illustration purposes only. The damper costs used from Table 5 do not encompasses the final retrofit investment.

\section{Discussion and Conclusions}

The distribution of dampers within a building is a critical decision, as damper placement affects structural response and the required damper investment. While a large number of FVD placement methods have been proposed, only limited comparisons of methods have been conducted. This paper evaluated and compared the effectiveness of several major damper placement methods considering structural and nonstructural performance in repair costs.

Six damper placement methods were selected for study. Each of these methods were chosen based on prevalence in literature and level of practicality. In order to compare the different placement techniques, the total 
viscous damping coefficient added to the structure was constrained to be the same value for each method. Two levels of total damping were selected: $15 \%$ and $30 \%$. This method of comparison may give different results to a methods based on damper cost.

This study was limited to considering linear FVDs in regular, CBF structures, in most cases distributing a fixed amount of damping coefficient. Within these constraints we can draw the following conclusions, which should be extended to other types of structure cautiously.

Damper placement distributions are similar for the four- and eight-storey structures. At $15 \%$ damping, the SSSA and the FSDA concentrate dampers in the middle storeys. The non-iterative methods generally exhibit an even distribution of dampers excluding the top storeys. For 30\% damping, all methods excluding uniform damping concentrate dampers in the lower and middle storeys. For the 16-storey building, the SEM and the ESEM allocate dampers to the middle storeys, while the iterative methods concentrate dampers in the middle to upper storeys.

Methods that concentrate dampers in a select number of storeys generally have poor ULS interstorey drift control at the storeys without dampers, and improved interstorey drift control at the storeys where dampers are concentrated (compared to uniform damping). The effect of the trade-off in EDPs on repair costs must be examined to measure the resulting changes in total-building seismic performance. Stiffness proportional damping and the ESEM exhibit a large interstorey drift concentration at storey 13 for the 16-storey building. This reveals a limitation of the placement methods, as stiffness discontinuities, weak storeys or other structural shortcomings may not be addressed. Methods that concentrate dampers in only a few storeys (the SSSA, the FSDA and the ESEM) exhibit large accelerations with respect to uniform damping at the storeys below the concentration of dampers.

The EDPs from the time history analyses allow earthquake repair costs to be evaluated using the FEMA P58 procedure. The main findings are summarized below:

1. No single damper placement method produces optimal EDP results for both interstorey drift and acceleration.

2. The iterative methods do not improve seismic performance.

3. The SEM, and notably the simplest method of uniform damping, generally produce repair costs that are more favorable than, or equal to, the other damper placement methods.

4. It appears unlikely that large shifts in total repair cost cumulative distribution functions can be achieved using an "optimal" damper placement method for low- and mid-rise buildings. Repair cost functions are more sensitive to the level of total damping than to the damper placement method used.

The iterative methods that seek to optimize seismic performance do not achieve this objective for totalbuilding performance. Optimizing for a single parameter may worsen another parameter that also has a significant impact on earthquake repair costs. Further complexities are introduced by the total repair cost being dependent on each building level. The methods optimize a local parameter, such as interstorey drift or velocity of each storey, assuming that the performance of each local parameter is independent. In contrast, the placement of a FVD in one storey can change the performance of the surrounding storeys. The concentration of dampers in a small number of storeys encouraged by the SSSA, the FSDA, and the ESEM has an overall negative effect on total-building seismic performance. The SEM and uniform damping generally produced the minimum repair costs. However, the iterative methods were able to achieve the desired damping ratios with a lower total damper cost. This suggests that, if the methods had been compared with methods based on total damper cost (rather than damping ratio), the performance of the iterative methods may have improved.

It appears that pursuing optimized linear FVD placement is unlikely to produce significant improvement in total earthquake repair costs for low- and mid-rise structures. To improve the total-building seismic performance of low- and mid-rise structures using linear FVDs, the SEM or uniform damping should be used with a large target total damping ratio. This is true for the simple and practical placement methods considered in this paper. It is possible that damper placement explicitly optimized for total building performance and considering nonlinear response may further reduce expected repair costs.

Damper placement optimization may be more successful for high-rise structures. Both absolute floor accelerations and interstorey drifts should to be considered in any optimization methods. Simplified fragility curves that estimate repair costs for each storey based on interstorey drift and acceleration could be developed using FEMA 
P-58 and used as objective functions. Discussion with industry professionals led to the opinion that for a damper placement method to be used frequently in practice, it must avoid extensive problem-specific tailoring or rely on complex tools and techniques not familiar to practicing engineers. It should be noted that any damper placement method is likely to be only a starting point for a detailed design. This further points to the use of simplified methods such as the SEM or uniform damping at this stage. Practical considerations, such as structural deficiencies of the unretrofitted structure, may further constrain the placement of dampers.

\section{Funding}

This work was supported by the Clarendon Fund (University of Oxford), and the Natural Sciences and Engineering Research Council of Canada [CGS M, PSG D]

\section{References}

1. Fierro EA, Miranda E, Perry CL. Behavior of nonstructural components in recent earthquakes. In: Architectural Engineering Conference (AEI) 2011. Oakland, California, United States: American Society of Civil Engineers (ASCE); 2011:369-377.

2. Dhakal RP. Damage to non-structural components and contents in 2010 Darfield earthquake. Bull New Zeal Soc Earthq Eng. 2010;43(4):404-411.

3. Miranda E, Mosqueda G, Retamales R, Pekcan G. Performance of nonstructural components during the 27 February 2010 Chile earthquake. Earthq Spectra. 2012;28(S1):S453-S471.

4. Kam WY, Pampanin S, Dhakal R, Gavin HP, Roeder C. Seismic performance of reinforced concrete buildings in the September 2010 Darfield (Canterbury) earthquake. Bull New Zeal Soc Earthq Eng. 2010;43(4):340-350.

5. Saatcioglu M, Tremblay R, Mitchell D, et al. Performance of steel buildings and nonstructural elements during the 27 February 2010 Maule (Chile) earthquake. Can J Civ Eng. 2013;40(8):722-734.

6. Baird A, Tasligedik AS, Palermo A, Pampanin S. Seismic performance of vertical nonstructural components in the 22 February 2011 Christchurch earthquake. Earthq Spectra. 2014;30(1):401-425.

7. FEMA. FEMA P-58, Seismic Performance Assessment of Buildings, Methodology and Implementation. Washington, D.C.; 2012.

8. Del Gobbo GM, Williams MS, Blakeborough A. Seismic Performance Assessment of Eurocode 8Compliant Concentric Braced Frame Buildings Using FEMA P-58. Eng Struct. 2018;155:192-208.

9. Del Gobbo GM, Williams MS, Blakeborough A. Seismic Performance Assessment of a Conventional MultiStorey Building. Int J Disaster Risk Sci. 2017;8(3):237-245.

10. CEN. Eurocode: Basis of structural design. 2010.

11. CEN. Eurocode 8: Design of structures for earthquake resistance - Part 1: General rules, seismic actions and rules for buildings. 2013.

12. Vargas R, Bruneau M. Effect of supplemental viscous damping on the seismic response of structural systems with metallic dampers. J Struct Eng. 2007;133(10):1434-1444.

13. Vargas RE, Bruneau M. Analytical Investigation of the Structural Fuse Concept. Buffalo, USA; 2006.

14. Pavlou E, Constantinou MC. Response of nonstructural components in structures with damping systems. $J$ Struct Eng. 2006;132(7):1108-1117.

15. Wanitkorkul A, Filiatrault A. Influence of passive supplemental damping systems on structural and nonstructural seismic fragilities of a steel building. Eng Struct. 2008;30(3):675-682.

16. Mayes R, Naguib W. Comparative Seismic Performance of Four Structural Systems and Assessment of Recent AISC BRB Test Requirements. taylordevices.com.

17. Dicleli M, Mehta A. Seismic performance of chevron braced steel frames with and without viscous fluid dampers as a function of ground motion and damper characteristics. J Constr Steel Res. 2007;63(8):11021115 .

18. Christopoulos C, Filiatrault A. Principles of Passive Supplemental Damping and Seismic Isolation. Pavia, Italy: IUSS Press; 2006.

19. Astrella MJ, Whittaker AS. The Performance-Based Design Paradigm. Buffalo, USA; 2005.

20. Whittle JK, Williams MS, Karavasilis TL, Blakeborough A. A comparison of viscous damper placement methods for improving seismic building design. J Earthq Eng. 2012;16(4):540-560.

21. Takewaki I. Optimal damper placement for minimum transfer functions. Earthq Eng Struct Dyn. 1997;26(February):1113-1124.

22. Hwang J-S, Lin W-C, Wu N-J. Comparison of distribution methods for viscous damping coefficients to buildings. Struct Infrastruct Eng. 2013;9(1):28-41. 
23. Lopez-Garcia D. A simple method for the design of optimal damper configurations in MDOF structures. Earthq Spectra. 2001;17(3):387-398.

24. Lopez Garcia D, Soong TT. Efficiency of a simple approach to damper allocation in MDOF structures. $J$ Struct Control. 2002;9(1):19-30.

25. Landi L, Conti F, Diotallevi PP. Effectiveness of different distributions of viscous damping coefficients for the seismic retrofit of regular and irregular RC frames. Eng Struct. 2015;100(1):79-93.

26. Levy R, Lavan O. Fully stressed design of passive controllers in framed structures for seismic loadings. Struct Multidiscip Optim. 2006;32(6):485-498.

27. Cimellaro GP, Retamales R. Optimal softening and damping design for buildings. Struct Control Heal Monit. 2007; 14:831-857.

28. McKenna F. OpenSees. 2017.

29. CEN. Eurocode 1: Actions on structures. 2010.

30. CEN. Eurocode 3: Design of steel structures. 2010.

31. Goulet CA, Haselton CB, Mitrani-Reiser J, et al. Evaluation of the seismic performance of a codeconforming reinforced-concrete frame building - from seismic hazard to collapse safety and economic losses. Earthq Eng Struct Dyn. 2007;36(13):1973-1997.

32. Uriz P, Mahin S. Toward Earthquake-Resistant Design of Concentrically Braced Steel-Frame Structures. Berkeley, USA; 2008.

33. Chen C, Mahin SA. Performance-Based Seismic Demand Assessment of Concentrically Braced Steel Frame Buildings. Berkeley, USA; 2012.

34. Jarrett J a., Judd JP, Charney F a. Comparative evaluation of innovative and traditional seismic-resisting systems using the FEMA P-58 procedure. J Constr Steel Res. 2015;105:107-118.

35. Kostic SM, Filippou FC. Section Discretization of Fiber Beam-Column Elements for Cyclic Inelastic Response. J Struct Eng. 2012;138(5):592-601.

36. Uriz P, Filippou FC, Mahin SA. Model for Cyclic Inelastic Buckling of Steel Braces. J Struct Eng. 2008;134(4):619-628.

37. Charney FA. Unintended consequences of modeling damping in structures. J Struct Eng. 2008;134(4):581592.

38. D'Aniello M, La Manna Ambrosino G, Portioli F, Landolfo R. Modelling aspects of the seismic response of steel concentric braced frames. Steel Compos Struct. 2013;15(5):539-566.

39. Karamanci E, Lignos D. Computational Approach for Collapse Assessment of Concentrically Braced Frames in Seismic Regions. J Struct Eng. 2014;140(8).

40. PEER. PEER NGA-WEST 2 Ground Motion Database. http://ngawest2.berkeley.edu/site. Published 2013.

41. Palermo M, Muscio S, Silvestri S, Landi L, Trombetti T. On the dimensioning of viscous dampers for the mitigation of the earthquake-induced effects in moment-resisting frame structures. Bull Earthq Eng. 2013;11(6):2429-2446.

42. Dall'Asta A, Tubaldi E, Ragni L. Influence of the nonlinear behavior of viscous dampers on the seismic demand hazard of building frames. Earthq Eng Struct Dyn. 2016;45:149-169.

43. Lavan O, Avishur M. Seismic behavior of viscously damped yielding frames under structural and damping uncertainties. Bull Earthq Eng. 2013;11(6):2309-2332.

44. Occhiuzzi A. Additional viscous dampers for civil structures: Analysis of design methods based on effective evaluation of modal damping ratios. Eng Struct. 2009;31(5):1093-1101.

45. Whittaker AS, Constantinou MC, Ramirez OM, Johnson MW, Chrysostomou CZ. Equivalent Lateral Force and Modal Analysis Procedures of the 2000 NEHRP Provisions for Buildings with Damping Systems. Earthq Spectra. 2003;19(4):959-980.

46. Aguirre JJ, Almazán JL, Paul CJ. Optimal control of linear and nonlinear asymmetric structures by means of passive energy dampers. Earthq Struct. 2013;42(3):377-395.

47. Lavan O, Levy R. Simple iterative use of Lyapunov's solution for the linear optimal seismic design of passive devices in framed buildings. $J$ Earthq Eng. 2009;13(December 2013):650-666.

48. Gidaris I, Taflanidis AA. Performance assessment and optimization of fluid viscous dampers through lifecycle cost criteria and comparison to alternative design approaches. Bull Earthq Eng. 2015;13(4):10031028.

49. RSMeans Online. Square Foot Estimator. www.rsmeansonline.com. Published 2017. Accessed April 10, 2017. 